\title{
Fatigue crack growth under non-proportional mixed-mode I + II. Role of compression while shearing.
}

\author{
Thomas Bonniot ${ }^{\mathrm{a}, \mathrm{b}}$, Véronique Doquet ${ }^{\mathrm{a}, *}$, Si Hai Mai ${ }^{\mathrm{b}}$ \\ ${ }^{a}$ Laboratoire de Mécanique des Solides, CNRS, UMR 7649, Université Paris-Saclay, Ecole Polytechnique, 91120 Palaiseau, \\ France \\ ${ }^{b}$ SNCF Innovation and Research, 1-3 avenue François Mitterrand, 93210 la plaine Saint Denis
}

\begin{abstract}
Mode I + II fatigue crack growth tests are run, following sequential or pseudo-sequential loading paths, representative of those computed for "squat type" cracks in rails. Stereo DIC provides the near-tip displacements, from which $\Delta K_{I}^{\text {effective }}$ and $\Delta K_{I I}^{\text {ef fective }}$ are derived. Compression while shearing extends coplanar growth, by slowing down the wear-induced rise of the effective mode mixity ratio, up to the critical value for which bifurcation occurs. The consideration of plasticity and contact and friction stresses improves crack paths predictions, compared to the maximum tangential stress criterion. The coplanar crack growth rate correlates well with a combination of $\Delta K_{I}^{\text {effective }}$ and $\Delta K_{I I}^{\text {effective }}$.
\end{abstract}

Keywords: Fatigue crack, mixed-mode I + II, friction, wear, rail steel

\section{Introduction}

The repeated passage of train wheels induces various types of fatigue cracks in railways. The most common defects are "squat-type" cracks, responsible for $50 \%$ of the rail replacements in France. These defects initiate from the running surface, along a highly sheared plane due to ratchetting-induced accumulation of shear strain inducing microstructural changes in a superficial layer [1]. These "squat-type" cracks -on which this paper focuses- keep propagating along a highly sheared plane even after crossing the transformed layer, and adopt a more or less semi-elliptical shape. An expensive periodic monitoring program and the replacement of damaged rail sections are necessary to ensure the safety of rail transportations. To improve the efficiency of such a maintenance program, reliable models to predict the crack paths and growth kinetics are needed, which is the goal of the present study. However, this remains a challenging problem, because, as illustrated below, those surface cracks in rails are loaded in non-proportional mixed-mode I + II + III in variable proportions along their front [2-4].

\footnotetext{
* Corresponding author.

Email adress: veronique.doquet@polytechnique.edu
} 
3D two-scale (global structure + local crack face interface problem) X-FEM numerical simulations have been performed by Mai et al. [4] for a semi-circular "squat" type crack deeper than $6 \mathrm{~mm}$, taking into account the frictional contact between crack faces and the rail bending. It appears that if thermal and residual stresses are not taken into account, the amplitudes of shear mode stress intensity factors (SIFs) are up to 10 times higher than that of mode I. Examples of computed loading paths in $K_{I}-K_{I I}$ plane are given in figure 1 for a $10 \mathrm{~mm}$-deep frictionless semi-circular crack inclined by $20^{\circ}$ relative to the vertical axis. This kind of loading path is approximately "pseudo-sequential". This term is chosen to denote a mode I cycle followed, without any overlap, by a reversed mode II cycle, superimposed with a static compression (blue curve on Fig. 1b, and Fig 1d), in reference to the usual denomination of "sequential" loadings for which the mode I cycle is followed by a mode II cycle, without any superimposed normal load (blue curve on Fig. 1a, and Fig 1c).

The loading path on squat-type cracks is shifted upwards -with an increasing amount of mode I- as the operating temperature decreases, because of a longitudinal tensile stress induced by the other rails welded at both ends. Residual axial tensile stresses inherited from the manufacturing process are also present in the rail head and contribute to mode I loading, while friction between the crack faces generally reduces the proportion of shear-mode loading. During the shearing stage, the crack is under normal compression due to the bending of the rail, with a compression reaching -100 $\mathrm{MPa}$ for a $10 \mathrm{~mm}$-deep crack (with residual stresses and no thermal stresses). Negative values of $K_{I}$-which have no physical meaning- are plotted only to remind this compression.

In previous studies, Mode I crack growth kinetics in R260 rail steel were determined, for positive and negative $\mathrm{R}$ ratios [5], as well as friction-corrected crack growth kinetics for fully-reversed in-phase mode II and III [5, 6]. However, neither pure mode I alone, nor combined mode II + III loadings alone could explain the crack paths and growth rates observed in rails. It is the combination of opening and shear modes, according to the complex loading paths described above that is responsible for it. This prompted the present work on fatigue crack growth in R260 rail steel under sequential or pseudo-sequential mode I + II.

Several experimental studies, motivated by similar rolling contact fatigue crack growth problems, were devoted to fatigue crack growth under sequential mode I + II [2, 7-11] or sequential mode I + III [12, 13]. The studies on mode I + II reported long and stable coplanar crack growth at low mode mixity ratios $\Delta K_{I I} / \Delta K_{I}$. This is not unexpected, since according to LEFM, close to a crack tip:

$$
\sigma_{\theta \theta}=\frac{\cos \left(\frac{\theta}{2}\right)}{\sqrt{2 \pi r}}\left[K_{I} \cos ^{2}\left(\frac{\theta}{2}\right)-\frac{3}{2} K_{I I} \sin (\theta)\right]
$$

and applying this equation to sequential mode I + II with $R_{I}=\frac{K_{I, \min }}{K_{I, \max }}=0, R_{I I}=\frac{K_{I I, \min }}{K_{I I, \max }}=-1$, it is 


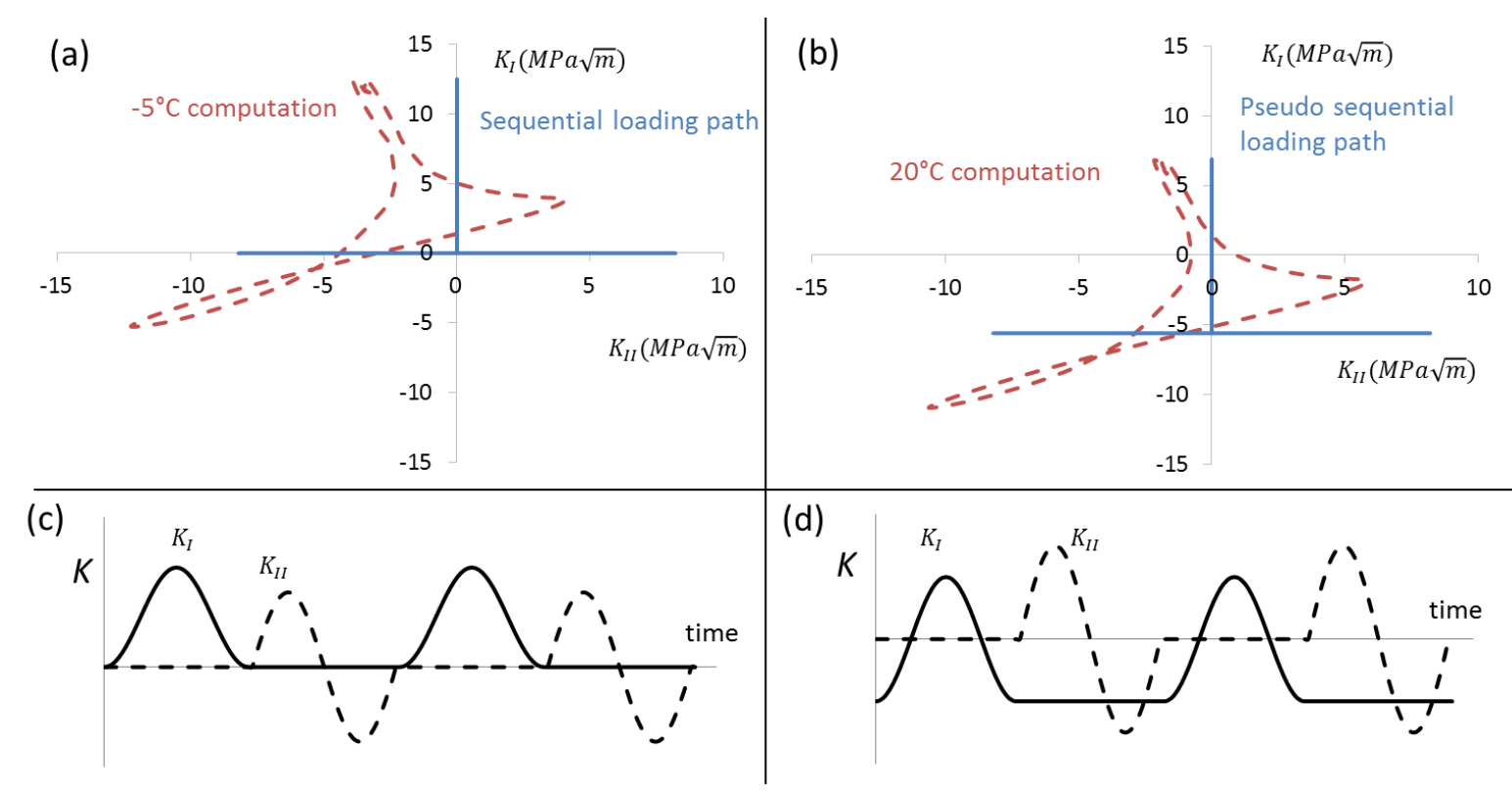

Figure 1: Computed loading paths and approximate sequential paths on a 10 mm-deep semi-circular, frictionless crack inclined by 20 degrees relative to the vertical axis in a rail, for (a) $-5^{\circ} \mathrm{C}$ and (b) $20^{\circ} \mathrm{C}$ operating temperatures. (c) time evolutions of the SIFs for sequential loading, and (d) for pseudo-sequential loading.

found that:

$$
\sigma_{\theta \theta ; \max }=\max \left(\frac{K_{I, \max }}{\sqrt{2 \pi r}}, \frac{2 K_{I I, \max }}{\sqrt{3} \sqrt{2 \pi r}}\right)=\max \left(\frac{\Delta K_{I}}{\sqrt{2 \pi r}}, \frac{\Delta K_{I I}}{\sqrt{3} \sqrt{2 \pi r}}\right)
$$

At angles of $0^{\circ}$ and $\pm 70.5^{\circ}$ respectively.

So, for $\Delta K_{I I} / \Delta K_{I}$ below $\sqrt{3}$, the peak value of the tangential stress over a cycle is found at zero degrees (see figure 2). In such conditions, according to the maximum tangential stress (MTS) criterion, stable coplanar growth should prevail in sequential mode I + II. Beyond this mode mixity ratio, the peak $\sigma_{\theta \theta}$; max shifts to $\pm 70.5^{\circ}$, so that bifurcation should occur.

Regarding the coplanar crack growth rate under sequential mode I + II (or mode I + III), all studies from the literature agree on the facts that:

- It correlates much better with the effective SIFs, corrected for closure and friction effects $\Delta K_{I}^{\text {effective }}$, $\Delta K_{I I}^{\text {effective }}$ than with their nominal values $\Delta K_{I}^{\text {nominal }}, \Delta K_{I I}^{\text {nominal }}$.

- It does not correlate well with either $\Delta K_{I}^{\text {effective }}, \Delta K_{I I}^{\text {effective }}$ (or $\Delta K_{I I I}^{\text {effective }}$ ) alone.

- Both the opening and shear modes contribute to the crack driving force.

Various expressions have thus been proposed for an "equivalent" $\Delta K$ combining $\Delta K_{I}$, and $\Delta K_{I I}\left(\right.$ or $\left.\Delta K_{I I I}\right)$. As an alternative, Doquet and Pommier [11] tried to predict the coplanar crack growth rate in mode I + 

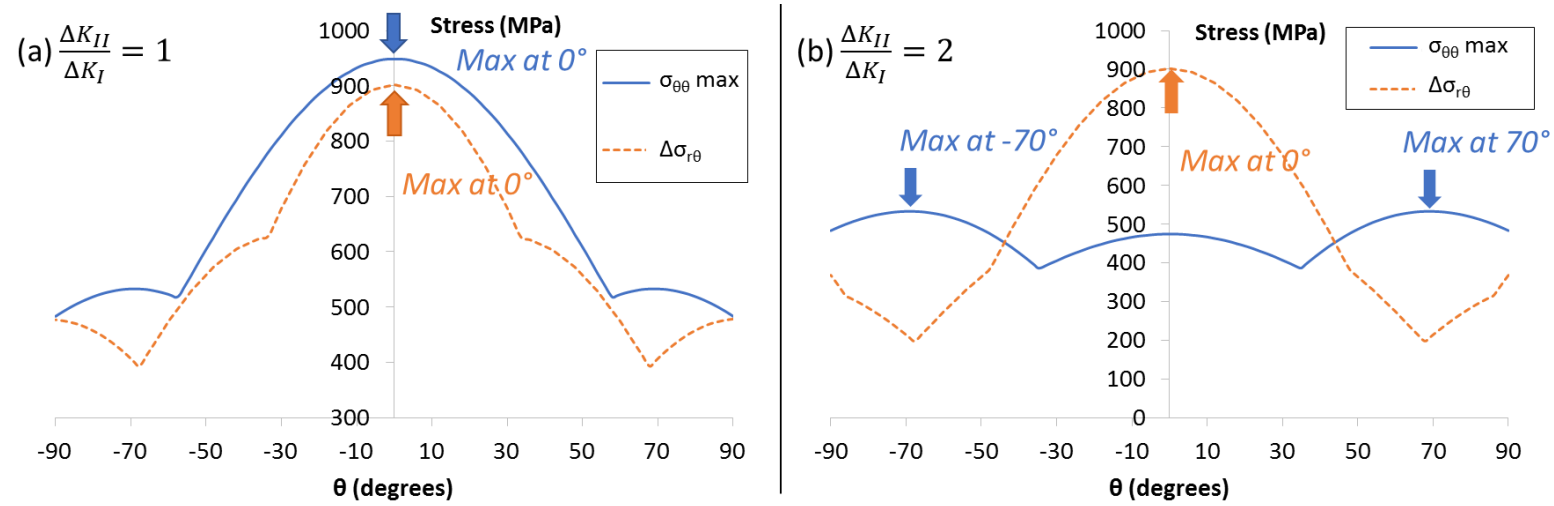

Figure 2: Angular distribution of $\sigma_{\theta \theta ; \max }$ and $\Delta \sigma_{r \theta}$ ahead of a crack submitted to sequential loading with (a) $\Delta K_{I I} / \Delta K_{I}=1$ and (b) $\Delta K_{I I} / \Delta K_{I}=2$ according to LEFM

II by a summation of the growth rates during the mode I and mode II parts of the cycle, and found that such a summation underestimates the growth rates. This was explained in terms of synergetic interactions of tensile and shear plastic flow at the crack tip [11], as well as in terms of tension-assisted, shear-driven damage [14], that no combination of $\Delta K_{I}$, and $\Delta K_{I I}$ would be able to capture.

Overall, fatigue crack growth under sequential mode I + II (or I + III) may seem rather well documented. However, all these studies used an $R$ ratio for the mode I cycles equal to zero, so that the influence of a compression during the shear-mode cycles, like that occurring on squat-type cracks, remains unknown. However, it has been shown by Tarantino, Beretta et al. [15-18] that a $90^{\circ}$ out-of-phase compression superimposed to a reversed out-of-plane shear-mode cycle reduces crack face friction -which was attributed to an enhancement of wear-, increases $\Delta K_{I I I}^{e f f e c t i v e}$, and favors shear-driven coplanar growth. It is thus worth investigating fatigue crack growth not only under sequential mode I + II $\left(R_{I}=0\right)$ but also under pseudo-sequential loading $\left(R_{I}<0\right)$ with a compression during the mode II cycle, as done in the present study.

After a presentation of the experimental procedures and outcome in terms of crack paths and growth rates, the complex effects of compression while shearing will be discussed, based on fractographic observations and elastic-plastic FE simulations. Crack face wear, crack tip plasticity, as well as contact and friction stresses along the crack face will be shown to influence the crack paths.

\section{Experimental procedures}

Fatigue crack growth tests were run on $R 260$ pearlitic rail steel ( $0.2 \%$ yield stress: $480 M P a$, tensile strength: $880 \mathrm{MPa}$ ) with the chemical composition reported in Table 1. Tubular specimens were used, with internal/external diameters of 23 and $25 \mathrm{~mm}$ respectively, a $16 \mathrm{~mm}$ long gage length, and a circular hole 
of $0.7 \mathrm{~mm}$ in diameter at mid height. Those were machined from the head of a new rail, along the rail direction. A 4 hour annealing treatment at $450^{\circ} \mathrm{C}$ in a vacuum was applied to relax, as far as possible, the residual stresses left by rail manufacturing and subsequent machining.

Table 1: Mass \% composition

\begin{tabular}{|c|c|c|c|c|}
\hline $\mathrm{C}$ & $\mathrm{Si}$ & $\mathrm{Mn}$ & $\mathrm{P}$ & $\mathrm{S}$ \\
\hline 0.72 & 0.32 & 1.08 & 0.015 & 0.022 \\
\hline
\end{tabular}

Before mounting the specimens on a triaxial servohydraulic machine $( \pm 100 \mathrm{kN}$ axial capacity, $\pm 600 \mathrm{Nm}$ for torsion, 0-1500 bars for internal pressure, not used here), a uniform white paint layer was first applied and polished with $P 1200$ sandpaper, to make it less glossy. Then a black ink speckle pattern was sprayed over a $50 \times 20 \mathrm{~mm}^{2}$ rectangular area around the center hole, using an airbrush. This speckle painting was used for stereo digital image correlation measurements of the near-tip displacement field, using two $2452 \times 2052$ pixels Pike cameras, with a pair of Tokina ATX-pro (100 $\mathrm{mm}$ focal length, aperture set at $f / 16$ ) lenses. Those were set at approximately $300 \mathrm{~mm}$ from the sample, with an angle of approximately $25^{\circ}$ between the two cameras, as shown on figure 3. With this setup, the resolution was approximately $7 \mu \mathrm{m}$ per pixel. Lighting was provided by an annular light source. The Vic-Snap software was used to capture (at preset load and/or torque levels during cycles) pairs of digital images. The Vic3D software was then used for stereo-correlation of these image pairs, with a subset size around $150 \mathrm{\mu m}$.

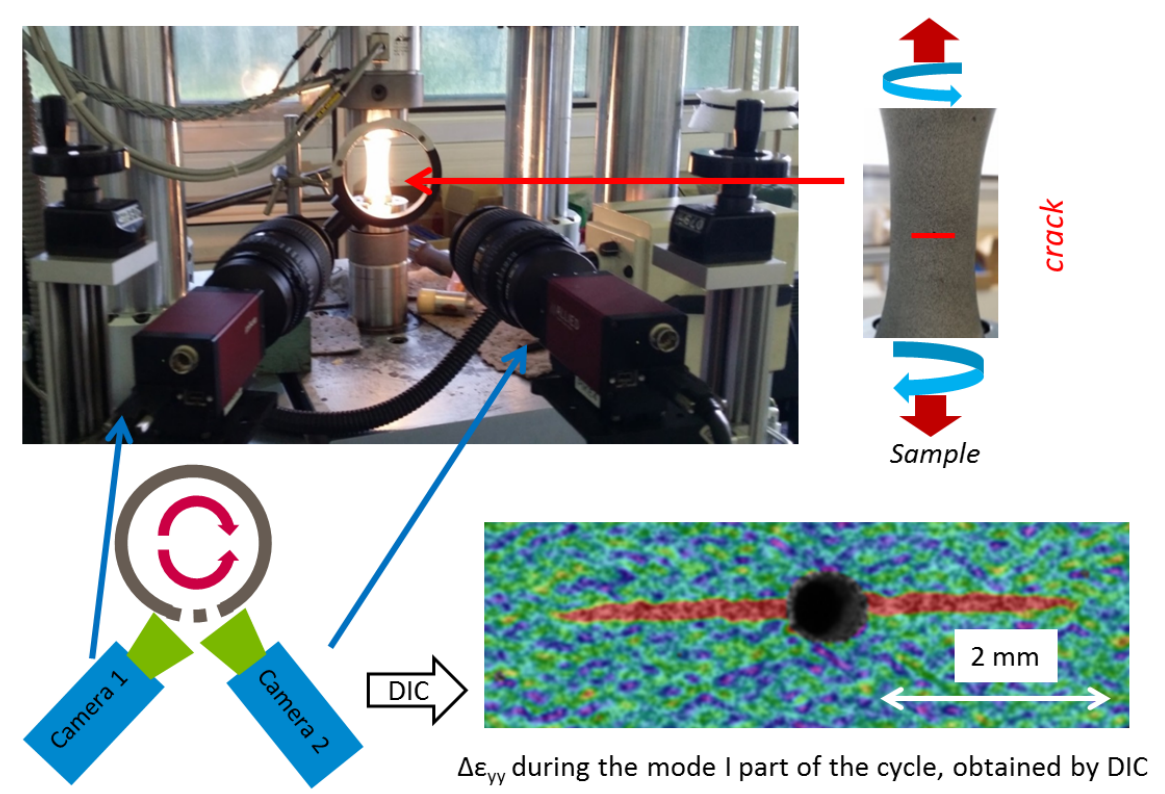

Figure 3: Experimental setup, with an example of strain field issued from DIC. 
A transverse crack was initiated and grown in mode I, over approximately $1.5 \mathrm{~mm}$ on each side of the hole, by cyclic tension $\left(R_{I}=0\right)$ with $\Delta K_{I}$ decreasing stepwise down to $10 M P a \sqrt{m}$ (by a manual control of the applied load, using the crack length estimated from the near-tip displacement field, as explained in Appendix A, and the analytical expression of $K_{I}$ for a transverse crack in a tube provided by Erdogan \& Ratwani [19] and reported in the handbook of Tada \& Paris [20]). Push-pull and torsion were then combined to achieve sequential $\left(R_{I}=0, R_{I I}=-1\right)$ or pseudo-sequential (static compression $F_{\min }<0$ during the reversed mode II cycle) loadings (figure 1) approaching those computed on a squat-type crack, but with only vertical or horizontal segments in $K_{I}-K_{I I}$ space. The loading frequency was $1 \mathrm{~Hz}$ for push-pull and reversed torsion. The axial load and torque amplitudes, nominal mode-mixity ratio, and outcome in terms of number of cycles and extent of coplanar growth at bifurcation (averaged over the two sides of the hole) are summarized in table 2 , ordered by rising nominal mode mixity ratio and rising torque range. Some tests were interrupted before bifurcation, in which case the reported extent of coplanar growth is a lower bound.

Specimen \# 9 was first used for a pseudo-sequential test that did not gave rise to significant crack growth (test $9_{a}$ ) and then used for a sequential test (test $9_{c}$ ).

For the experiments \# 4 to \# 9, a slight asymmetry in specimen tightening in its clamping device might have induced bending, and thus a static axial stress changing the mode I load ratio $R_{I}$ (which is not accounted for in table 2). This artifact was suppressed in further tests. More details are available in [5]. However, this bending does not affect the following analysis, since the effective stress intensity factors measured by DIC are used, as explained below.

Table 2: Test conditions and outcome for sequential and pseudo-sequential loadings. The length of coplanar growth is averaged on the two cracks initiated from the hole.

\begin{tabular}{|c|c|c|c|c|c|c|}
\hline Exp. \# & $\begin{array}{l}\text { Max / Min axial } \\
\quad \text { force }(\mathrm{kN})\end{array}$ & $\begin{array}{l}\text { Torque } \\
\text { (N.m) }\end{array}$ & $\frac{\Delta K_{I I}^{n o m}}{\Delta K_{I}^{n o m}}$ & $\begin{array}{c}\text { Cycles of } \\
\text { coplanar } \\
\text { growth }\end{array}$ & $\begin{array}{c}\text { Coplanar } \\
\text { growth }(\mathrm{mm})\end{array}$ & $\begin{array}{l}\frac{\Delta K_{I I}^{\text {effective }}}{\Delta K_{I}^{\text {effective }}} \\
\quad \text { at } \\
\text { bifurcation }\end{array}$ \\
\hline $9_{c}$ & $13 / 0$ & \pm 90 & 1.2 & 240000 & $>4.3$ & I \\
\hline 8 & $10 / 0$ & \pm 90 & 1.6 & 70000 & $>4$ & / \\
\hline 19 & $10 / 0$ & \pm 90 & 1.6 & 51000 & $>6$ & I \\
\hline 11 & $11 / 0$ & \pm 160 & 2.5 & 3000 & 0.6 & $1.7-2.6$ \\
\hline 5 & $10 / 0$ & \pm 150 & 2.6 & 15000 & 0.4 & $1.8-3$ \\
\hline 4 & $7 / 0$ & \pm 110 & 2.7 & 180000 & 1 & $2-2.3$ \\
\hline $9_{a}$ & $10 /-5$ & \pm 140 & 2.4 & 250000 & $\lesssim 0.1$ & I \\
\hline 10 & $11 /-5$ & \pm 160 & 2.5 & 20000 & 4.5 & $1.8-1.9$ \\
\hline 6 & $10 /-5$ & \pm 150 & 2.6 & 128000 & 3.8 & $2-2.3$ \\
\hline
\end{tabular}

A method based on the projection of the measured displacement field over William's series expansion of the near tip displacement field at order 7 was used to locate both crack tips, using image pairs captured at peak tensile load and after a small elastic unloading (see Appendix B or [21]). Iterations were performed 
over the crack tip position to minimize the error between theoretical and measured fields. However, this method was not used to evaluate the effective SIFs because:

- The assumption of stress-free crack faces on which it relies is not valid for sequential nor pseudosequential loading, since friction occurs while shearing (even without compression, due to crack roughness).

- It tends to overestimate the SIFs, because it does not consider crack tip plasticity [21].

The derivation of the effective SIFs in such cases is a problem in itself, which has been discussed in detail in [21]. The method which was specifically developed is just briefly explained below.

To determine the effective SIFs, the profiles of relative opening and sliding displacement jump amplitudes between two rows of virtual extensometers parallel to the crack, and located at a distance $\delta=0.2 \mathrm{~mm}$ above and below are used. In order to capture the influence of crack tip plasticity, displacement jump profiles are computed by elastic-plastic frictionless FE computations, and an inverse method is used: these computations are made for various opening or shear loading ranges (each one corresponding to a certain $\Delta K_{I}$, or $\Delta K_{I I}$ ), seeking the loading ranges for which the computed displacement profiles fits best the measured ones. Corrective constant terms $B_{I}$ or $B_{I I}$ are added to take into account crack face contact and friction stresses (eq. 3 \& 4).

$$
\begin{gathered}
{\left[\left[U_{y}\right]\right]=\left[\left[U_{y}^{\text {Plastic }}\right]\right]\left(\Delta K_{I}\right)+B_{I}} \\
{\left[\left[U_{x}\right]\right]=\left[\left[U_{x}^{\text {Plastic }}\right]\right]\left(\Delta K_{I I}\right)+B_{I I}}
\end{gathered}
$$

These equations reflect the fact that if the crack is closed/locked due to normal compression and friction, the first term on the right hand-side vanishes $\left(\Delta K_{I}=0 / \Delta K_{I I}=0\right)$, and the cracked sample behaves as if it was crack-free: the displacement jump between the two lines (distant of $2 \delta=0.4 \mathrm{~mm}$ ) is then non-zero and constant. By finding the combination of $\left[\left[U^{\text {Plastic }}\right]\right]$ and $B$ which gives the best fit, one is able to estimate the effective SIFs. By repeating such an analysis at various points during a given cycle, the time evolutions of $K_{I}^{\text {effective }}(t)-K_{I I}^{\text {effective }}(t)$ are found, as well as the effective loading path $\left(K_{I}^{\text {effective }}(t)\right.$ versus $\left.K_{I I}^{\text {effective }}(t)\right)$, the effective amplitudes $\Delta K_{I}^{\text {effective }}, \Delta K_{I I}^{\text {effective }}$, and the effective mode mixity ratio: $\Delta K_{I I}^{\text {effective }} / \Delta K_{I}^{\text {effective }}$ during this cycle. By repeating this process at various stages of each test, the evolution of the effective mode mixity ratio can be monitored. More details on this method, validated/calibrated against FE-generated displacement fields (for which the effective SIFs were known), and compared favorably with other approaches, can be found in [21]. 


\section{Experimental results}

In this section, the test results will be presented, starting with "raw data": the crack paths. Then, since the crack growth rates have to be correlated with SIFs corrected for closure and friction effects, the effective loading paths issued from the measured displacement fields will be presented, before the analysis of the crack growth kinetics. Fractographic observations will close this section devoted to experimental facts.

\subsection{Crack paths}

A typical crack path is shown on Fig. 4. Coplanar growth over distances which are indicated in Table 2 is first observed, before bifurcation at angles around $\pm 50-55^{\circ}$. Observations in the thickness of the tubes (fig $4 \mathrm{~b}$ ) showed that during coplanar growth, the cracks remained normal to the tube axis and that their front remained straight and nearly normal to the outer surface.

As expected, for sequential loadings with nominal mode mixity ratios smaller than 1.6 , more than 4 $\mathrm{mm}$ coplanar growth is observed, while for nominal mode mixity ratios larger than 2.5 , bifurcation occurs after less than $1 \mathrm{~mm}$ coplanar growth. For pseudo-sequential loadings, that is when a $66 \mathrm{MPa}$ compressive stress (13\% of the yield stress) is present while shearing, the outcome is either crack arrest (less than 0.1 $\mathrm{mm}$ growth during 250000 cycles for the smallest torque range) or extended coplanar growth, in spite of a nominal mode mixity ratio higher than 2.5. For example, the sequential test \#11 corresponds to the same torque amplitude and peak tensile load as the pseudo-sequential test \#10, but coplanar growth is observed over $0.6 \mathrm{~mm}$ in the former, and $4.5 \mathrm{~mm}$ in the latter. The same effect is observed for sequential test \#5 (no more than $0.4 \mathrm{~mm}$ coplanar growth) and the pseudo-sequential test \#6 (3.8 $\mathrm{mm}$ coplanar growth). These results clearly show that compression extends coplanar growth, and that the crack path prediction cannot be based on the nominal mode mixity ratio.

\subsection{Effective loading paths}

Figure 5 compares the nominal and effective loading paths issued from DIC post-treatment for the sequential test \#11 and the pseudo-sequential test \#10 with similar peak tensile load and torque range.

For the sequential test, the ratio $U_{I I}=\Delta K_{I I}^{\text {effective }} / \Delta K_{I I}^{\text {nom }}$ is 0.64 , which means that even without any applied compression, the contact, interlocking and friction of crack faces asperities significantly reduces the effective SIFs. Besides, a non-zero $K_{I}$ appears at both maximum and minimum $K_{I I}$. This is a dilatancy effect, which can be easily reproduced in FE simulations on rough cracks [22]. In this case, $\Delta K_{I}^{\text {dilatancy }}$ is around $8 \%$ of $\Delta K_{I I}^{\text {effective }}$.

For the pseudo-sequential test, $U_{I I}$ drops to 0.16 , because crack face friction is enhanced by compression. For the pseudo-sequential test \#9a, $U_{I I}$ even drops to zero: there is no sliding displacement at the crack tip, and thus $\Delta K_{I I}^{\text {effective }}$ vanishes. This is due to compression, which, combined to a low $\Delta K_{I}^{\text {effective }}$ explains 


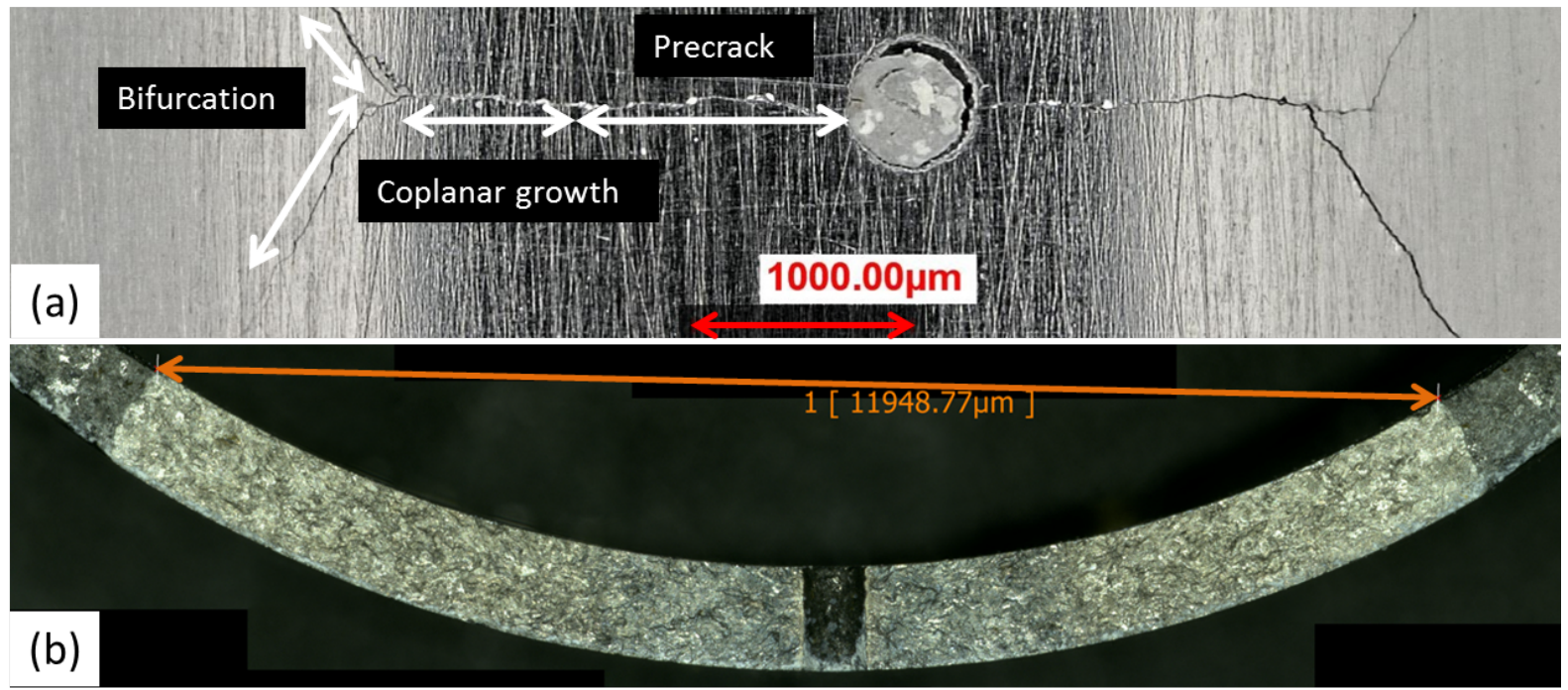

Figure 4: Typical crack path observed during the tests. a) on the outer surface and b) in the thickness

the observed crack arrest.

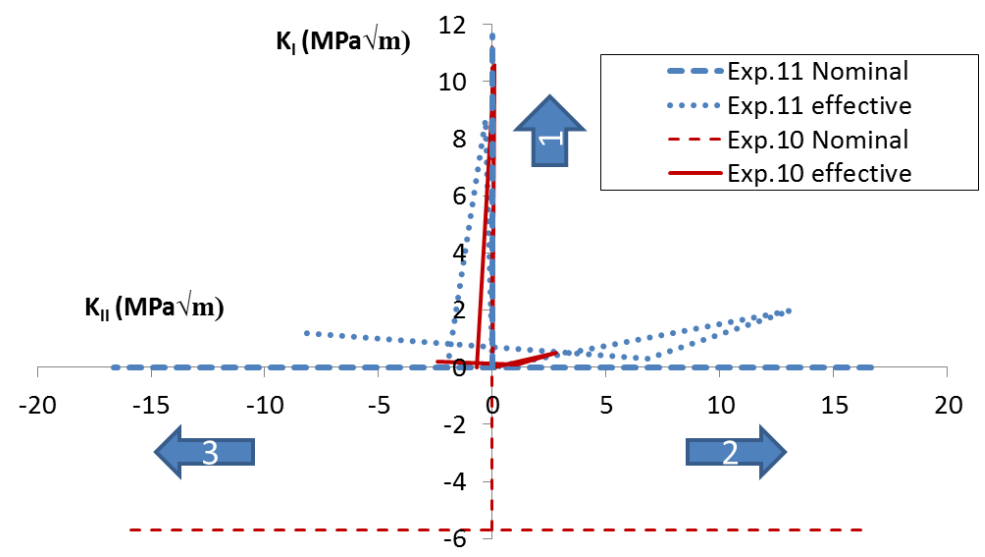

Figure 5: Nominal and effective loading paths for the sequential test \#11 and the pseudo-sequential test \#10 with similar peak tensile and torque range. Negative values of $K_{I}$ are plotted only to remind the compressive stage. The arrows and numbers show the order of loading sequences.

Figure 6 shows the measured effective fractions of the loading range: $U_{I}=\Delta K_{I}^{\text {effective }} / \Delta K_{I}^{\text {nom }}$, for the mode I part of the cycle, and $U_{I I}$ for the mode II part of the cycle, for all the tests. $U_{I}$ is found to rise slightly with $\Delta K_{I}^{\text {effective }}$. No correlation of this parameter with $\Delta K_{I I}$ was observed. $U_{I I}$ is found to rise sharply with $\Delta K_{I I}^{e f f e c t i v e}$, starting with near zero values, even for tests without any normal compression (like test \#9c), and reaching at most 0.5 . 

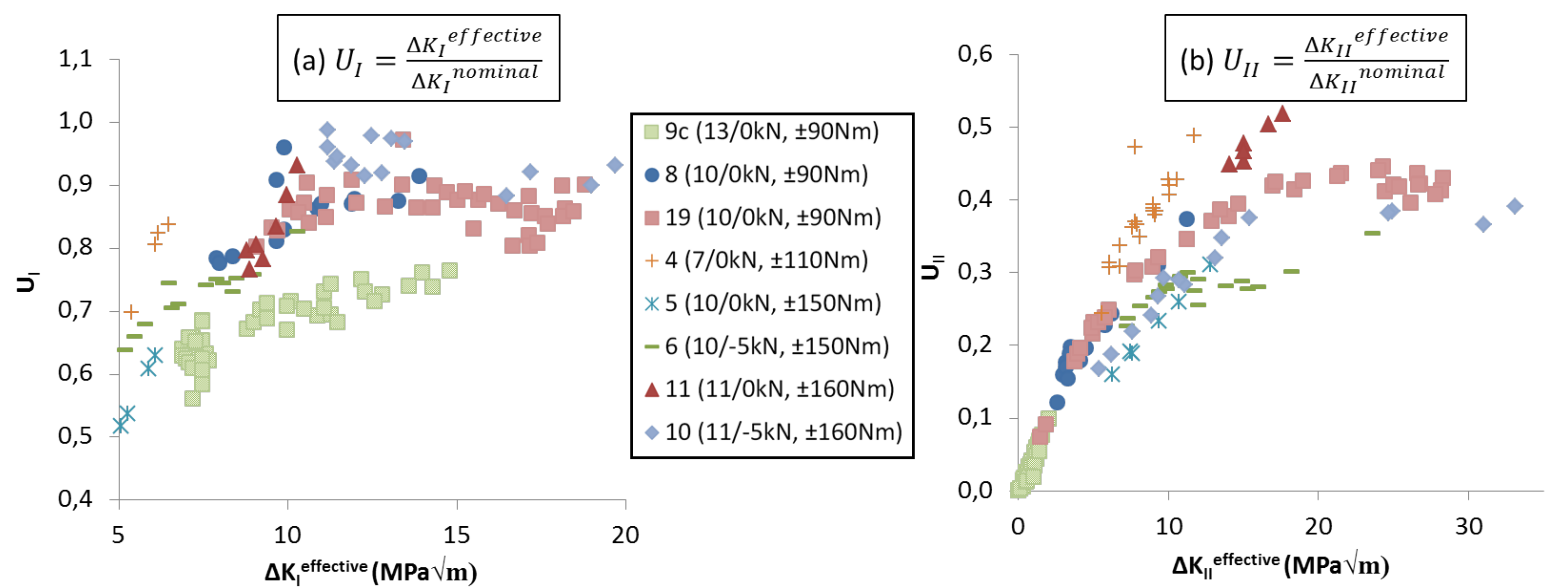

Figure 6: Effective fractions of the loading range: (a) for the mode I part of the cycle and (b) for the mode II part of the cycle.

Figure 7.a compares the evolution of the effective mode mixity ratio with the crack length for the sequential test \#11 and pseudo-sequential test \#10 which shared the same peak tensile load and torque range and the same nominal mode mixity ratio of 2.5. Considering the evolutions of $\Delta K_{I}$ and $\Delta K_{I I}$ (obtained from [20]), for a smooth and frictionless transverse crack in a tube submitted to constant tensile load and torque amplitudes, the mode mixity ratio is not expected to change as the crack grows. However, during both tests, the effective mode mixity ratio was initially much smaller than its nominal value (around 1.3 for the sequential test \#11, and 0.5 for the pseudo-sequential test \#10) and progressively rose, up to a value around 2 for which bifurcation occurred.

The same type of evolution was observed for all the tests (see figure 7.b), with a final value of the effective mode mixity ratio at bifurcation ranging from 1.6 to 3 (since image capture for DIC was performed at discrete numbers of cycles, and the image resolution is limited, the moment of bifurcation is known within a certain range). The reason why this value is often higher than that of 1.73 predicted by LEFM will be discussed later on. The observed rise in the effective mode mixity ratio is attributed to a progressive wear of crack face asperities, which reduces asperities interlocking and friction and thus increases $\Delta K_{I I}^{\text {effective }}$. Note that in presence of compression while shearing, the rise of the effective mode mixity ratio is much slower than without compression, as discussed below. This explains why such a compression extends coplanar growth (23000 cycles and $4.5 \mathrm{~mm}$ coplanar growth, instead of 3000 cycles and $0.6 \mathrm{~mm}$ coplanar growth).

The effective SIFs will now be used to analyse the measured crack growth rates.

\subsection{Crack growth rates}

In previous studies, Paris equations for fatigue crack growth in mode I [5] and in-phase mode II + III [6] in the same rail steel have been determined as, respectively: 

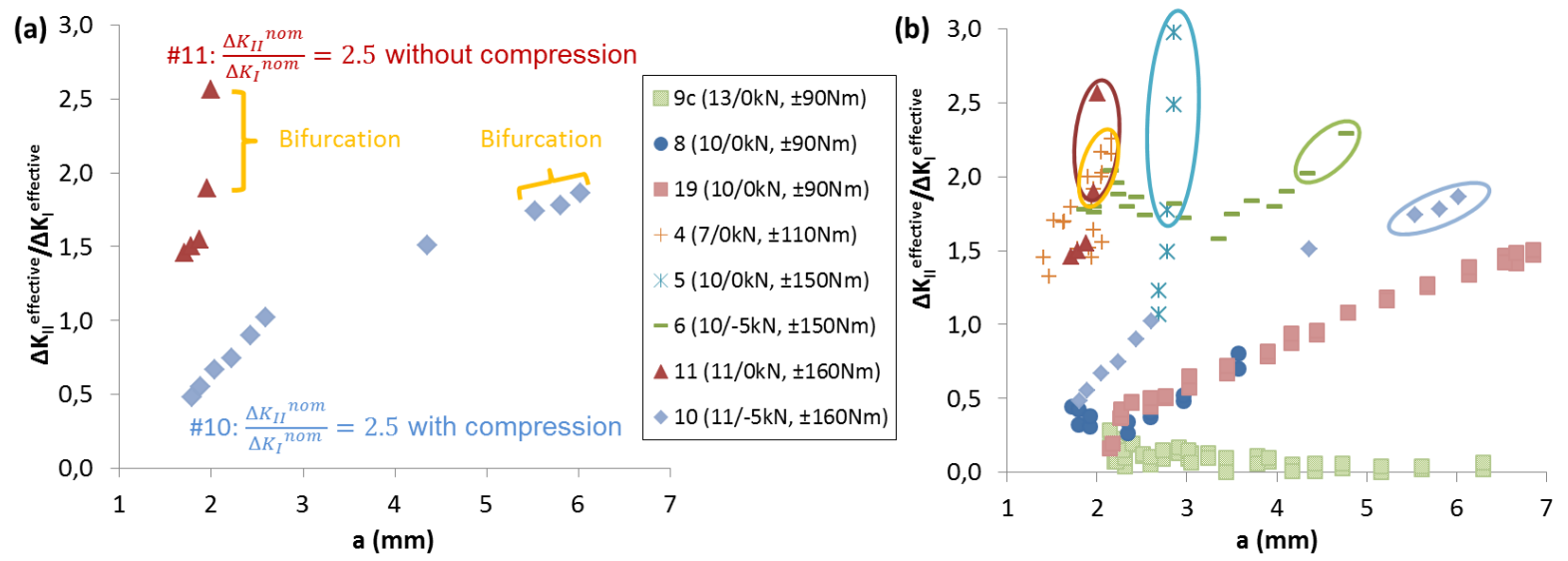

Figure 7: Evolution of the effective mode mixity ratio with the crack length (a) for sequential test \#11 and pseudo-sequential test \#10 (similar peak tensile load and torque range) and (b) for all tests (bifurcations are marked by circles).

$$
\begin{gathered}
\frac{d a}{d N}=C_{I}\left(\Delta K_{I}^{\text {effective }}\right)^{m_{I}} \\
\frac{d a}{d N}=C_{\text {shear }}\left(\Delta K_{\text {shear }}^{\text {effective }}\right)^{m_{\text {shear }}} \\
\Delta K_{\text {shear }}^{\text {effective }}=\sqrt{\Delta K_{I I}^{\text {effective }}+\frac{1}{1-\nu} \Delta K_{I I I}^{\text {effective }}{ }^{2}}
\end{gathered}
$$

Eq. 6 was found to be satisfactory for any combination of mode II and mode III [5], including the case of pure mode II, and can thus be used here as a reference. To predict the crack growth rate in sequential or pseudo sequential mode I + II, a summation of the growth rates during the mode I and mode II part of a cycle seems reasonable:

$$
\frac{d a}{d N}=C_{I}\left(\Delta K_{I}^{\text {effective }}\right)^{m_{I}}+C_{\text {shear }}\left(\Delta K_{\text {shear }}^{\text {effective }}\right)^{m_{\text {shear }}}
$$

Since coplanar growth in mixed-mode II + III was observed only at high $\Delta K$, equation 6 had to be extrapolated at lower amplitudes. The growth rates computed with equation 8 (considering that $\Delta K_{I I I}=0$ in the present tests) are compared to the measured ones on Fig. 8. The correlation is reasonable (correlation coefficient of 0.88 ), but in average, equation 8 overestimates the growth rates (a slope of 1.377 is obtained).

A slightly better correlation of the measured crack growth rates can also be obtained with:

$$
\Delta K_{\text {eq }}^{\text {effective }}=\sqrt{\left(\Delta K_{I}^{\text {effective }}\right)^{2}+\left(\Delta K_{\text {shear }}^{\text {effective }}\right)^{2}}
$$

as shown by Fig 9, on which the data-points for mode I and for in-phase mode II + III are also plotted 


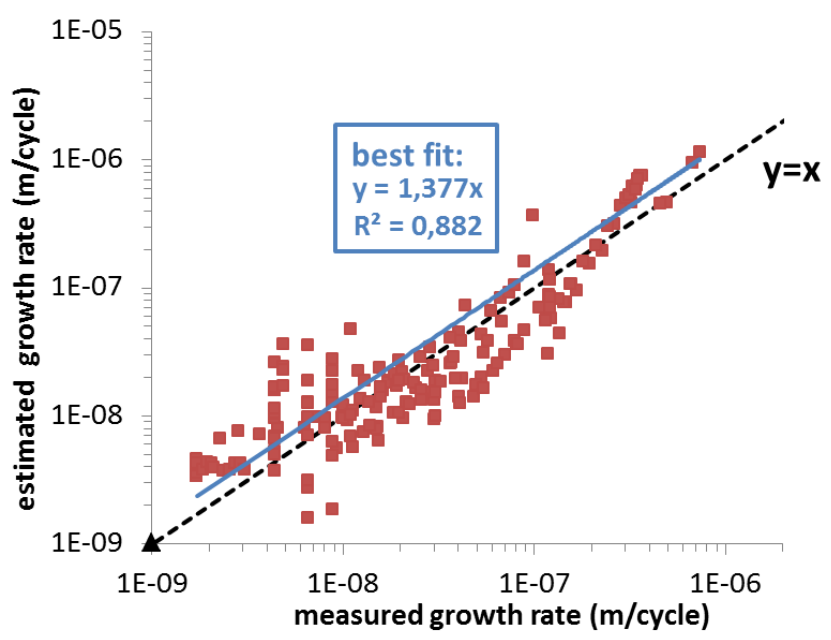

Figure 8: Measured versus estimated coplanar crack growth rate in sequential or pseudo-sequential loading using a summation of mode I and mode II contributions. The closer the points to the identity line $(y=x$, dashed line), the better.

for comparison. The exponent of the power law fitted for coplanar mixed-mode I + II was slightly higher than for mode I, but still below that found for mode II + III.

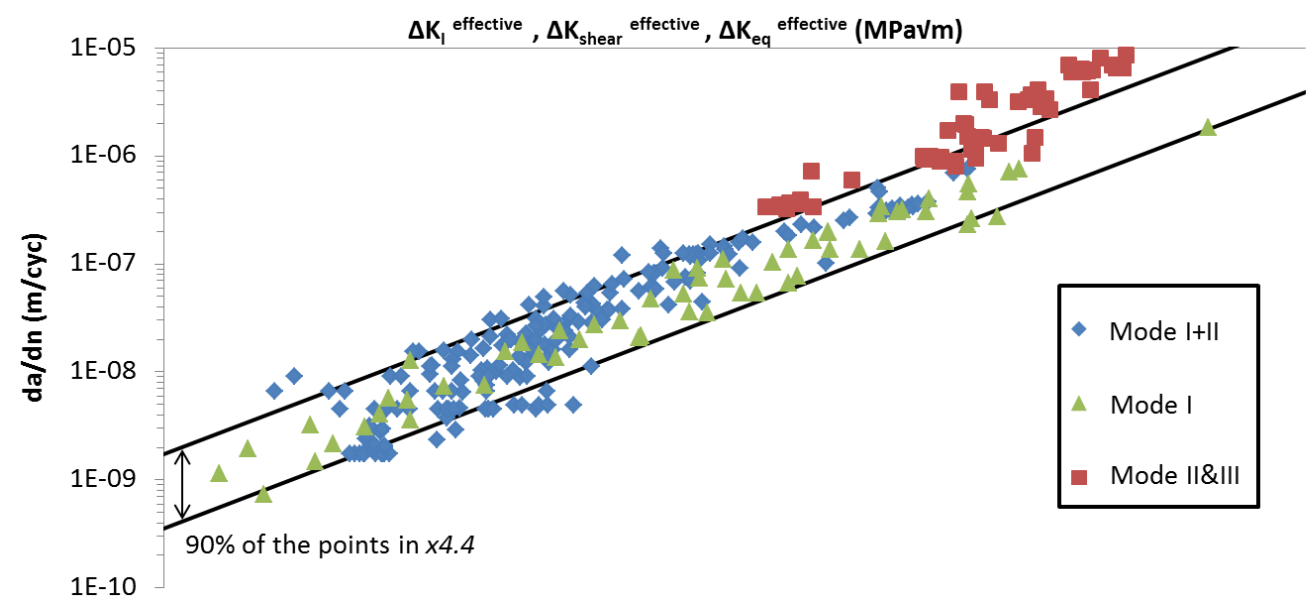

Figure 9: Correlation of measured crack growth rates for mode I, mode II + III and mode I + II with $\Delta K_{I}^{\text {effective }}, \Delta K_{\text {shear }}^{\text {effective }}$ or $\Delta K_{e q}^{e f f e c t i v e}$, respectively. No units for confidentiality reasons.

Fractographic observations are helpful to explain the large difference between nominal and effective SIFs (see Fig. 6b) and the effect of compression while shearing. These observations will be summarized below.

\subsection{Fracture surfaces}

Figure 10a shows two types of wear debris on the fracture surface after the sequential test \#4: whitish, detached and more or less rounded debris (similar to those reported by Smith and Smith in pure mode II 
[23]) as well as scale-like debris, still adherent to the substrate, and whose detachment and further crushing and rolling might produce the small rounded debris.

Fig 10b shows completely flattened areas, with clusters of what looks like a white powder on the fracture surface after the pseudo-sequential test \#6. EDS chemical analysis clearly shows that dark-looking areas on SEM images captured using the backscattered electron (BSE) signal -which enhance chemical contrast - correspond to oxygen-rich areas (namely: oxidized wear debris), while white-looking areas correspond to bare metal.

The comparison of the BSE images of the sequential sample \#11 (which looks uniformly gray) and pseudo-sequential sample \#10 (much more contrasted) suggests a more uniform oxidation in the former, which also looks less mated, while the latter exhibits large areas of severely worn bare metal, with long and marked wear scars and a few areas where strongly oxidized debris cluster (fig 11a\&b).

For experiments with a low $\Delta K_{I I}^{\text {effective }}$ (for example \#9), the crack faces remained mode I-like, without any wear (fig 10c). Intermediate fracture surfaces were also obtained: highly worn away from the tip, in areas which underwent many cycles, and unaltered close to the tip, where the surfaces were more recently created and the relative sliding displacements smaller.

\section{Discussion}

In this section, the effects of compression while shearing on crack face friction, oxidation and wear will first be discussed, based on the fractographic observations presented above. Then, the problem of crack path prediction will be discussed, and several versions of the maximum tangential stress criterion (with or without taking crack tip plasticity and crack face contact stresses into account) will be compared in terms of their ability to predict the observed crack paths. Finally, cyclic crack tip plasticity in R260 steel under sequential or pseudo-sequential loading mixed-mode loading will be analyzed through finite element simulations in order to discuss the measured crack growth rates.

\subsection{Effect of compression on crack face friction, oxidation, and wear}

According to Archard's wear law [24], the worn volume is proportional to the contact pressure, $\sigma_{N}$, and the relative sliding displacement of the two mating bodies, $[\mathrm{u}]$ :

$$
V_{\text {wear }}=k \sigma_{N}[u]
$$

According to LEFM, for mode II, the near-tip tangential displacement reads:

$$
u_{x}=(1+\nu) \frac{K_{I I}}{E} \sqrt{\frac{r}{2 \pi}} \sin \left(\frac{\theta}{2}\right)\left(k+1+2 \cos ^{2}\left(\frac{\theta}{2}\right)\right)
$$



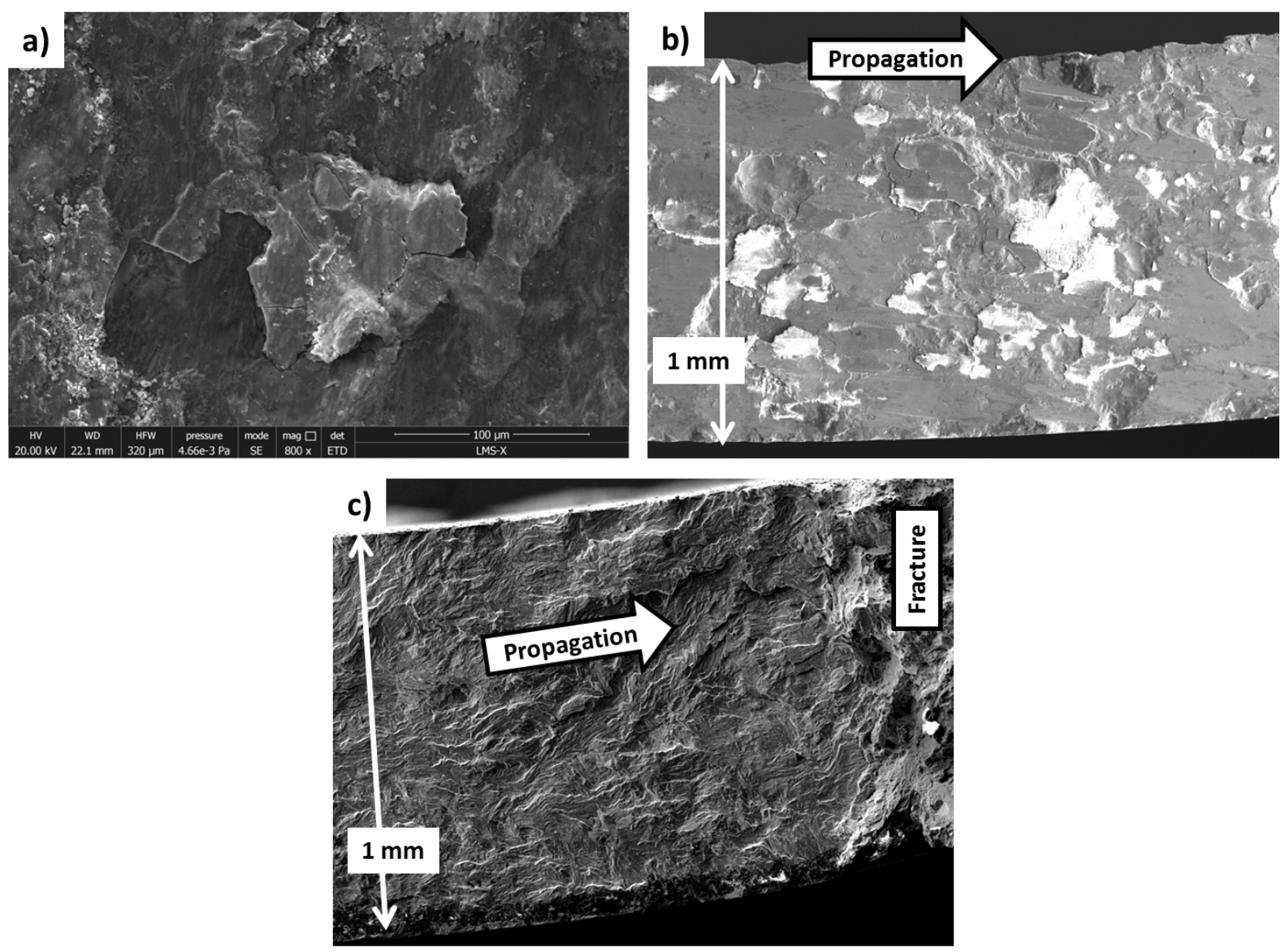

Figure 10: Fracture surfaces: (a) small, rounded and detached, as well as scale-like debris, sequential test \#4, (b) flattened asperities after pseudo-sequential test \#6, (c) unaltered surface after test \#9.

Where $k=\frac{3-\nu}{1+\nu}$ in plane stress. During one cycle, at distance $x$ behind the crack tip $\left(\theta= \pm 180^{\circ}\right)$, the relative sliding displacement range is thus:

$$
\Delta[u(x)]=\frac{8 \Delta K_{I I}^{\text {effective }}}{E} \sqrt{\frac{x}{2 \pi}}
$$

For a center crack in a plate under a reversed shear stress, $\Delta \tau$, and normal compression, $\sigma_{N}$, and considering a Coulomb's friction coefficient $\mu$ :

$$
\begin{gathered}
\Delta K_{I I}^{\text {effective }}=\left(\Delta \tau-2 \mu \sigma_{N}\right) \sqrt{\pi a} \\
V_{\text {wear }}=k \sigma_{N}[u(x)]=8 k \sigma_{N} \frac{\Delta K_{I I}^{\text {effective }}}{E} \sqrt{\frac{x}{2 \pi}}=8 k \sigma_{N} \frac{\left(\Delta \tau-2 \mu \sigma_{N}\right) \sqrt{\pi a}}{E} \sqrt{\frac{x}{2 \pi}}
\end{gathered}
$$

From eq. 14, we see that, on the one hand, compression while shearing should enhance wear for a given 


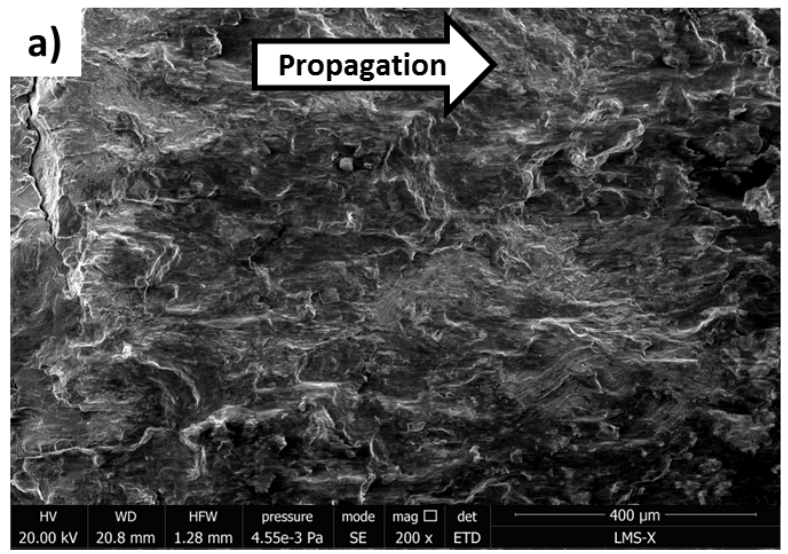

$\# 11,6000$ cycles, $11 / 0 \mathrm{kN}, \pm 160 \mathrm{Nm}$

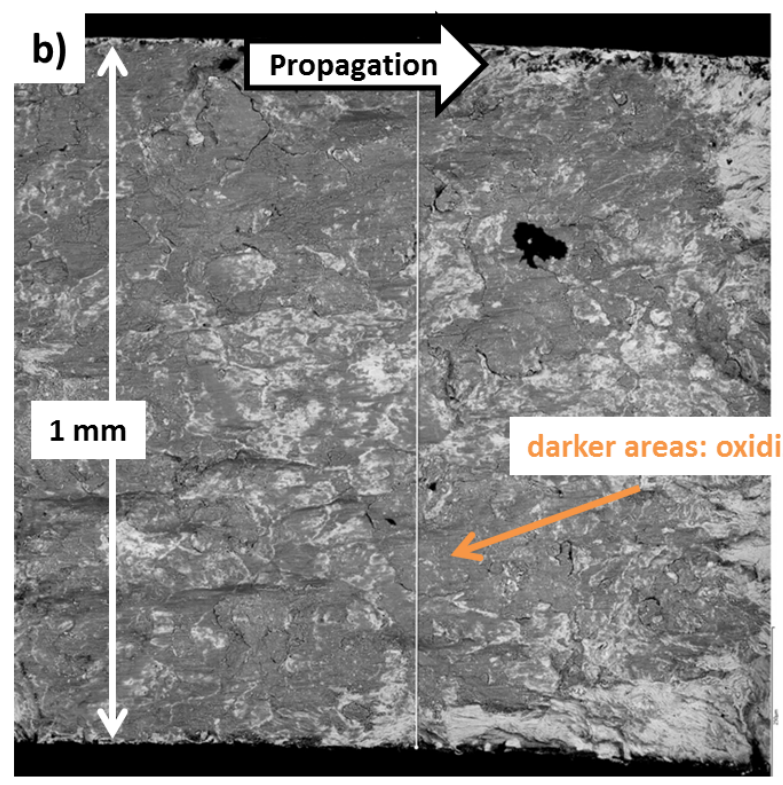

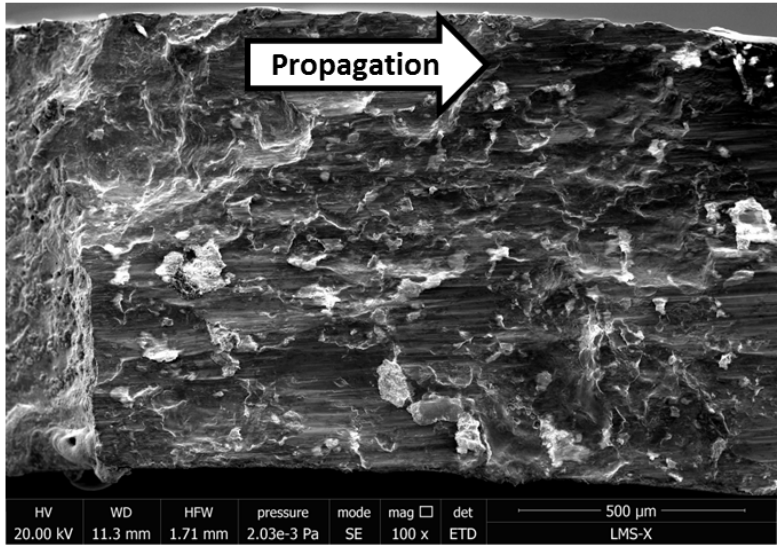

\#10, 23000 cycles, 11/-5 kN, $\pm 160 \mathrm{Nm}$

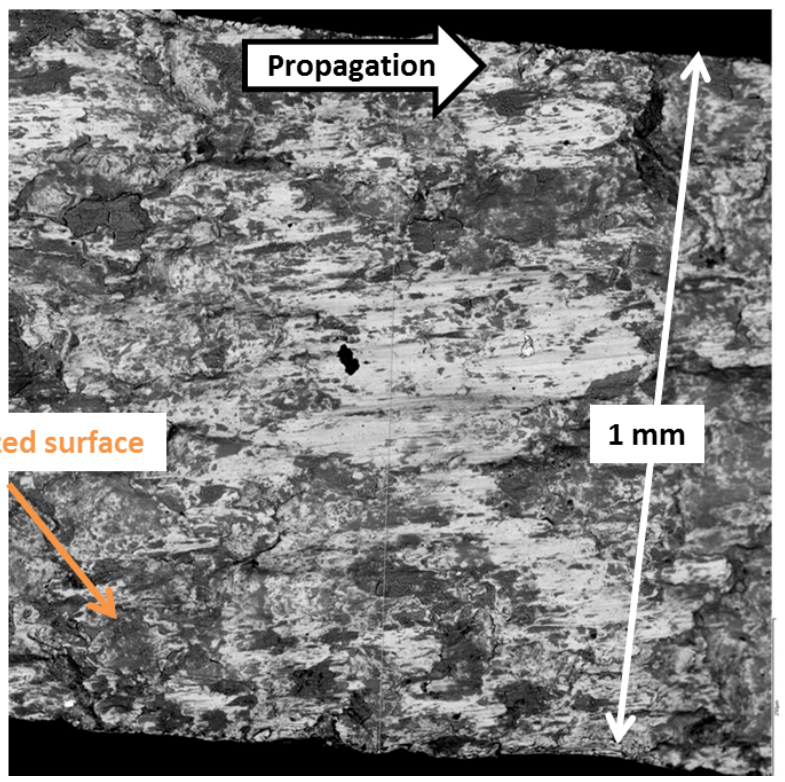

Figure 11: Fracture surfaces: (a) compared aspect of samples \#10 and \#11, (b) compared oxydation of samples \#10 and \#11

sliding displacement range, but on the other hand, it should reduce the relative sliding displacement range along the crack face. Overall, the effect of a compressive stress on wear can be estimated from the sign of the derivative:

$$
\frac{\partial V_{w e a r}}{\partial \sigma_{N}} \propto \Delta \tau-4 \mu \sigma_{N}
$$

which changes, depending on the relative value of $\Delta \tau$ and $4 \mu \sigma_{N}$ : there is a set of values which maximizes wear. For small shear loading ranges compression should reduce wear, because it mostly reduces the sliding displacement range (for the pseudo-sequential test \#9a, it even reduced it to zero at the crack tip, leading to crack arrest), while for high shear stress ranges, it should enhance it. 
However, both the friction and wear coefficients, $\mu$ and $k$, have been reported to vary (actually, to decrease, for Ti64 alloy [25] and figure 4.6 of [26]) as the normal compression rises, because of associated changes in the tribological mechanisms: 1) increased trapping of fretting debris, 2) hindering of oxygen access to the contact surface, 3) switch from abrasive towards adhesive wear... In the present study, the amount of debris on the fracture surface of samples submitted to pseudo-sequential loadings actually seemed very important, and the oxidation of these surfaces less homogeneous, with large areas of bare metal.

The overall effect of a compression while shearing on crack faces wear is thus the result of a complex interplay between multiple, and sometimes opposite effects, quite difficult to predict. This is a problem, because, as shown above, wear -to a large extent- controls the crack paths. Recent works from Arnaud et al $[27,28]$ and other, such as [29-34], suggest that it might be possible to simulate crack face wear, including the effect of a third body layer (oxidized debris), and this would certainly be very useful.

\subsection{Crack path prediction}

As mentioned above, the determination of the effective SIFS (and effective mode mixity ratio) and their evolution in engineering application remains a challenge. For reliable predictions of the crack path, it is however necessary, since tests with nominally similar mode mixity ratios (like tests \#10 and \#11 or \#5 and \#6) can lead to very different crack paths and growth rates. This conclusion was also reached in [22], where it was explained based on FE simulations of different loading paths on rough cracks with contact and friction effects. Assuming that this problem is solved and that the effective mode mixity ratio is known, how to predict the crack path under sequential or pseudo-sequential loadings?

As recalled in the introduction, if a purely elastic behavior is assumed, coplanar growth is predicted by the maximum tangential stress (MTS) criterion, as long as $\Delta K_{I I}^{\text {effective }} / \Delta K_{I}^{\text {effective }}$ remains below 1.73. However, in the present study, bifurcation most often occurs for a value close to 2 or even slightly higher. This can be explained by crack tip plasticity, which, as underlined by Dahlin \& Olsson [35] can significantly redistribute the stress field ahead of the tip, change the angular distribution of the tangential stress, and thus the angular position of its peak. They proposed a version of the MTS criterion, taking this plasticity-induced stress redistribution into account, and denoted by MTSp. When this criterion is

applied to sequential mixed-mode I + II, it does not predict a unique critical $\Delta K_{I I}^{\text {effective }} / \Delta K_{I}^{\text {effective }}$ at bifurcation, but a material-dependent value, ranging typically from 1.73 (negligible crack tip plasticity) to more than 2 .

A 2D, plane stress FE model with a center crack of length $a=1$ to $8 \mathrm{~mm}$ in a 30 by $30 \mathrm{~mm}^{2}$ large plate loaded in push-pull and shear, with $10 \mu \mathrm{m}$ wide triangular linear elements around the crack tip, and unilateral 
contact conditions along the crack face was developed (fig 12). Elastic-plastic constitutive equations with non-linear kinematic hardening previously-identified for $R 260$ rail steel (which shows negligible isotropic hardening [6]) were used to run simulations of sequential or pseudo-sequential mode I + II loadings. The applied tensile and shear stresses, $\sigma_{n}(t)$ and $\tau(t)$, were adjusted so as to reproduce the measured effective loading paths $K_{I}^{\text {effective }}-K_{I I}^{e f f e c t i v e}$, using the expressions for a crack in an infinite plate: $K_{I}=\sigma_{n} \sqrt{\pi a}$, $K_{I I}=\tau \sqrt{\pi a}$.

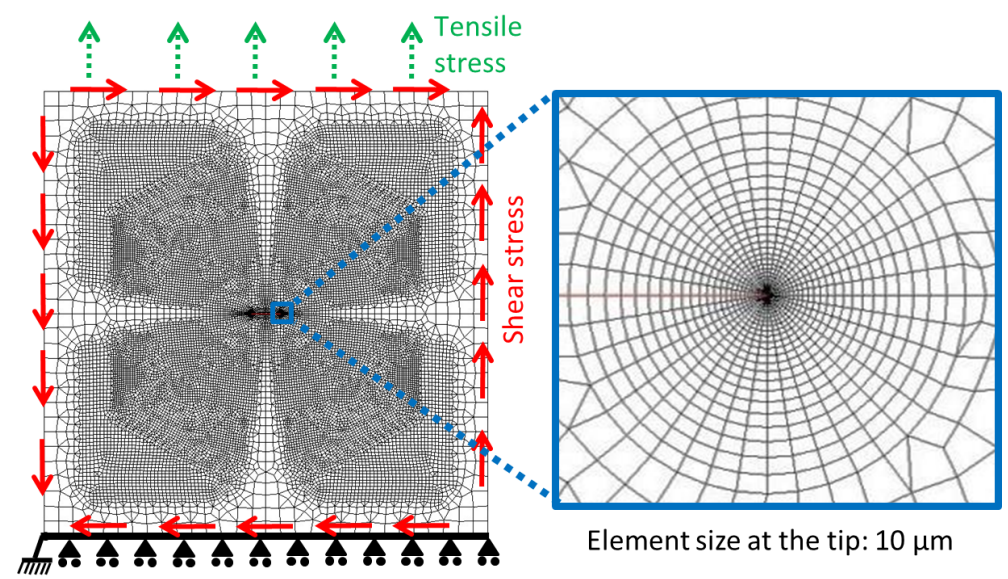

Figure 12: FE model used for 1) Estimation of the effective SIFs from the measured CTOD \& CTSD profiles, 2) crack path prediction and 3) analysis of plastic coupling between mode I and II

Figure 13 compares the angular distributions of the peak tangential stress, $\sigma_{\theta \theta ; \max (t)}, 40 \mu m$ ahead of the tip for $\Delta K_{I}=7.5 \mathrm{MPa} \sqrt{m}$ and $\Delta K_{I I} / \Delta K_{I}=2$, issued from elastic or elastic-plastic computations (crack length $a=2 \mathrm{~mm}$ ). Crack-tip plasticity reduces the height of the peaks at $\pm 70.5^{\circ}$, and should thus increase the critical $\Delta K_{I I} / \Delta K_{I}$ for bifurcation, which lies around 2 for $R 260$ steel. This "critical value" actually slightly depends on the extent of crack tip plasticity, and can reach 2.1 in this material.

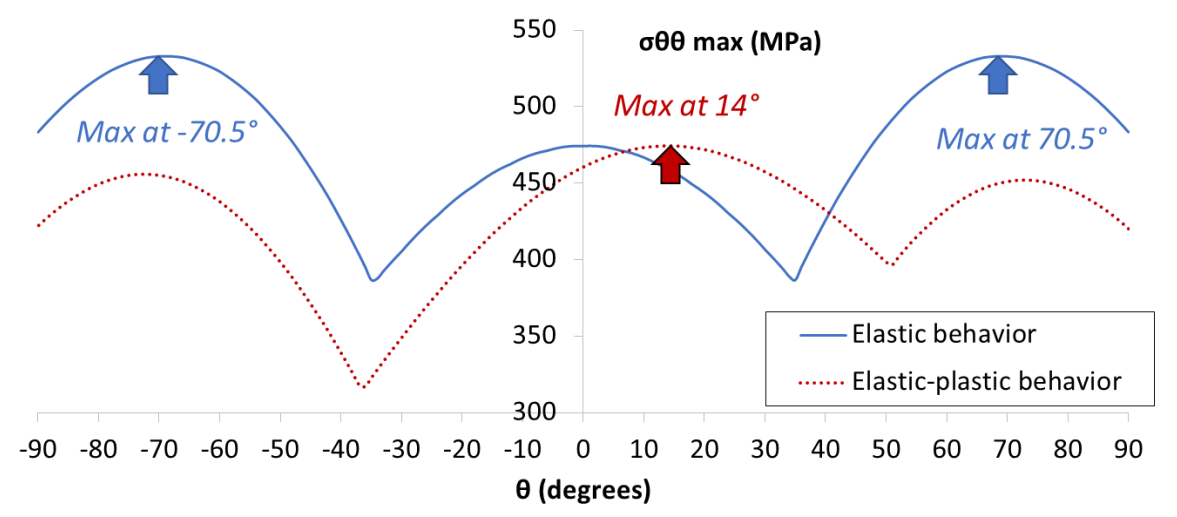

Figure 13: Effect of plasticity on the angular distribution of the tangential stress for sequential mode I + II loading, with $\Delta K_{I}=7.5 \mathrm{MPa} \sqrt{m}$ and $\Delta K_{I I} / \Delta K_{I}=2$. 
On the one hand, the MTSp criterion predicts effective mode mixity ratios at bifurcation in better agreement with the experimental values than the MTS criterion (see table 2). On the other hand, it does not strictly predict coplanar growth: the angular maximum of the peak tangential stress on Fig 13 does not appear at $0^{\circ}$, but at $14^{\circ}$. Note that the elastic-plastic angular distribution shown on Fig 8.a of Dahlin \& Olsson's paper [35] was not symmetrical either with respect to zero. This is a consequence of the residual stress field left by the mode II half cycle preceding the last simulated mode I cycle, which induces this asymmetry. Had the loading path been simulated in the reverse direction, the peak would appear at $-14^{\circ}$.

The slight deviation from coplanar growth predicted by the MTSp criterion below the "critical value" around 2 grows with $\Delta K_{I I} / \Delta K_{I}$. Such early deviations by a few degrees were not observed in the experiments. This explains why the rate of successful predictions with less than $15^{\circ}$ error reported in table 3 is only $53 \%$ of the 30 analyzed cases (9 tests, with 2 crack tips each, and several moments analysed: during coplanar growth, at bifurcation or after bifurcation), while the rate of successful predictions with less than $30^{\circ}$ error reaches $90 \%$. The latter figure reflects the capacity of the MTSp criterion to predict the right moment of bifurcation, even though the bifurcation angle is not well predicted, as discussed below. For comparison, the rate of success within $30^{\circ}$ was $83 \%$ with the MTS criterion.

Table 3: Percentage of succesful predictions of crack path within a given error range, for the MTSp criterion, considering the contact and friction stresses or not.

\begin{tabular}{|c|c|c|c|}
\hline \multirow{2}{*}{ Within } & \multicolumn{3}{|c|}{$\%$ of succesfull predictions } \\
\cline { 2 - 4 } & MTS & MTSp & MTSp with contact \& friction stresses \\
\hline $15^{\circ}$ & 60 & $53 \%$ & $73 \%$ \\
\hline $30^{\circ}$ & 83 & $90 \%$ & $97 \%$ \\
\hline
\end{tabular}

The accuracy of the MTSp criterion depends on the accuracy of the constitutive equations used for the analysis. Two factors can reduce this accuracy: 1) an extrapolation to higher strain ranges than the range in which the model was identified (in the present case, up to $2 \%$ in $\Delta \epsilon$ and $7.7 \%$ in $\Delta \gamma$ while the strain ranges computed at the crack tip reach $10 \%$ and $14 \%$, respectively) and 2) an effect of non-proportional loading (extra hardening) on the cyclic behaviour. Indeed, the constitutive model used here was identified from push-pull and reversed torsion tests, but not from combined, sequential loadings. However, extra hardening under sequential tension/compression and shear loading is expected to be limited in such a ferritic-pearlitic steel $[36]$.

The fact that the observed bifurcation angles are $\pm 50-55^{\circ}$ rather than $\pm 70.5^{\circ}$ according to the MTS criterion (or $\pm 76.6^{\circ}$ according to the maximum energy release rate criterion, or $\pm 77.3^{\circ}$ using the local symmetry criterion) is probably not due to plasticity, which rather seems to shift the position of the peaks towards slightly larger angles. It does not seem to be due to the dilatancy effects mentioned above, since 
for $\Delta K_{I}^{\text {dilatancy }}$ around $8 \%$ of $\Delta K_{I I}^{\text {effective }}$, the predicted reduction of the bifurcation angle is less than $4^{\circ}$.

Leblond \& Frelat [37] found that, within the framework of LEFM, a normal compression that closes a crack loaded in mode II should not modify its bifurcation angle, but only the curvature of the branch after incipient kinking. A possible influence of such a normal compression and of the associated friction stress along the crack face was however investigated here, taking cyclic plasticity into account, through the simulation of sequential or pseudo-sequential loadings with the same peak tensile stress and same shear stress range.

Figure 14 illustrates the effects of contact and friction stresses on the angular distribution of $\sigma_{\theta \theta ; \max (t)}$, $40 \mu \mathrm{m}$ ahead of a crack submitted to mode I + II loading with $\Delta K_{I I}^{\text {effective }} / \Delta K_{I}^{\text {effective }}=2$. Compared to the angular distribution found for a compression-free and frictionless crack, the distribution found when compression is present while shearing exhibits a reduced peak height at $\pm 73^{\circ}$, while the central peak is slightly enhanced and closer to $0^{\circ}$. When both compression and friction are considered (using a friction coefficient of 0.5 ), the central peak moves even closer to zero degrees, but is much reduced in height, while the two other peaks become substantially higher and shifted to $\pm 65^{\circ}$. The consideration of contact and friction stresses when using the MTSp criterion seems thus likely to bring the predicted crack paths closer to the observed paths (central peak closer to $0^{\circ}$, and the other two peaks shifted to lower angles). The contact and friction stresses for each test were thus estimated approximately for each test as:

$$
\begin{gathered}
\tau_{\text {friction }}=\left(1-U_{I I}\right) \tau_{\text {applied }} \\
\sigma^{\text {contact }}=\sigma^{\text {compression }}+\sigma^{\text {closure }}=\sigma^{\text {compression }}+\left(U_{I}-1\right) \Delta \sigma
\end{gathered}
$$

in which $\sigma^{\text {compression }}$ denotes the applied normal stress during the pseudo-sequential loadings, and $\sigma^{\text {closure }}$ the mean contact stress due to closure effects, present even during the sequential tests. These values were taken into account in elastic-plastic FE simulations, and new predictions of the crack paths were made. This approach significantly improved the percentage of successful predictions, as shown in table 3: $73 \%$ within $15^{\circ}$ (instead of $53 \%$, without considering contact and friction stresses) and $97 \%$ (instead of 90\%) within $30^{\circ}$.

\subsection{Coplanar crack growth rates}

Contrary to what was observed in a previous study on sequential mixed-mode I + II, run on a pearlitic steel [11] no obvious synergetic effect between mode I and mode II loadings due to plastic interactions is found in the ferritic-pearlitic steel of the present study. In other words, the coplanar crack growth rates are not systematically higher than those estimated by a summation of the growth rates during the mode I and mode II parts of a cycle. 


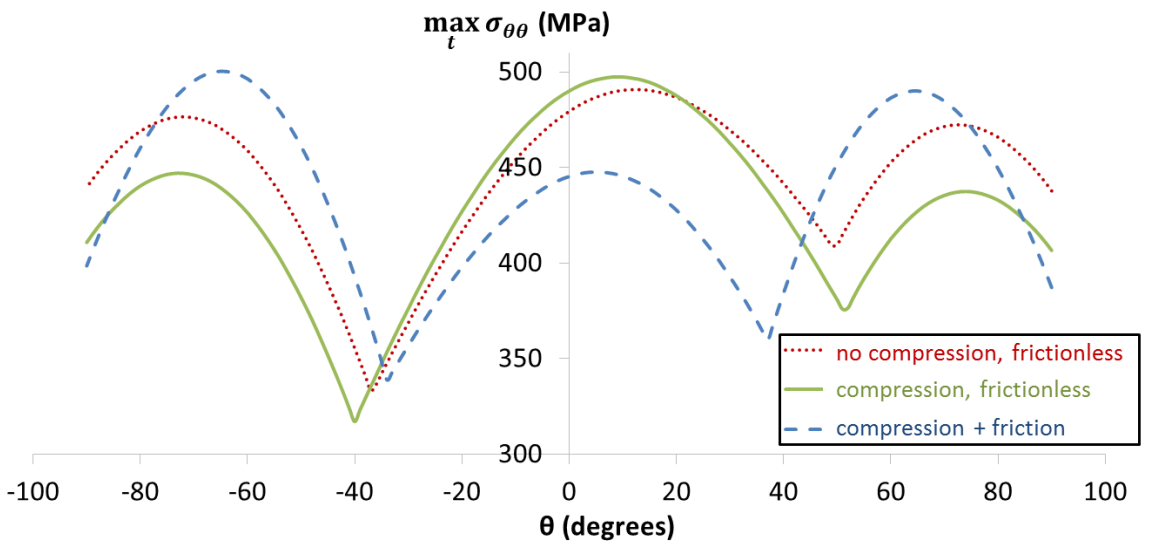

Figure 14: Effect of contact and friction stresses along the crack face on the angular distribution of $\sigma_{\theta \theta ;}$ max $40 \mu m$ ahead of a crack submitted to sequential loading with $\Delta K_{I I}^{\text {effective }} / \Delta K_{I}^{\text {effective }}=2$ (elastic-plastic computations).

In order to investigate the mode I/mode II plastic interactions in the present material, as well as the effect of compression, twelve cycles of pure mode I $\left(R_{I}=0\right)$, pure mode II $\left(R_{I I}=-1\right)$, sequential $\left(R_{I}=0\right.$, $\left.R_{I I}=-1\right)$ or pseudo-sequential loading (-66 MPa compression while shearing, $R_{I I}=-1$ ) were simulated, with $\Delta K_{I}=9 M P a \sqrt{m}$, and $\Delta K_{I I}=18 M P a \sqrt{m}$. The evolutions of the CTOD and CTSD, computed at the first node, $25 \mu \mathrm{m}$ behind the crack tip, as well as of the mean value and range of the shear strain $25 \mu \mathrm{m}$ ahead of the tip, were then compared (Fig 15). Note that frictionless contact conditions are used, so that the comparisons are made for similar effective SIFs.

Compared to pure mode II, sequential loadings is found to trigger shear strain ratchetting ahead of the crack tip (Fig 15a). This can qualitatively be explained based on the elliptical shape and movements of von Mises yield locus during cyclic plastic flow, and on the fact that plastic flow occurs normal to this yield locus (Fig 16). Since R260 steel exhibits mostly kinematic hardening with negligible isotropic hardening, the yield locus does not grow or shrink, but only shifts in the direction of plastic flow.

During the second half of a fully reversed mode II cycle, shear plastic flow shifts the yield locus towards the left, so that during the subsequent mode I cycle, the border of the yield locus is met at a point for which the normal is inclined towards the right. The subsequent mode I cycles thus induce a positive shear strain increment, which explains the ratcheting effect shown on Fig 15a. Ratchetting would occur in the opposite direction if the loading path was followed in the opposite direction. The effect of pseudo-sequential loading on the mean shear strain is much smaller, which, as explained below, is due to a different direction of plastic flow (with a reduced lateral shift of the yield locus) during the mode II cycle. Anyway, contrary to tension-driven fatigue damage, which is influenced by the mean axial strain, shear-driven damage is gen- 


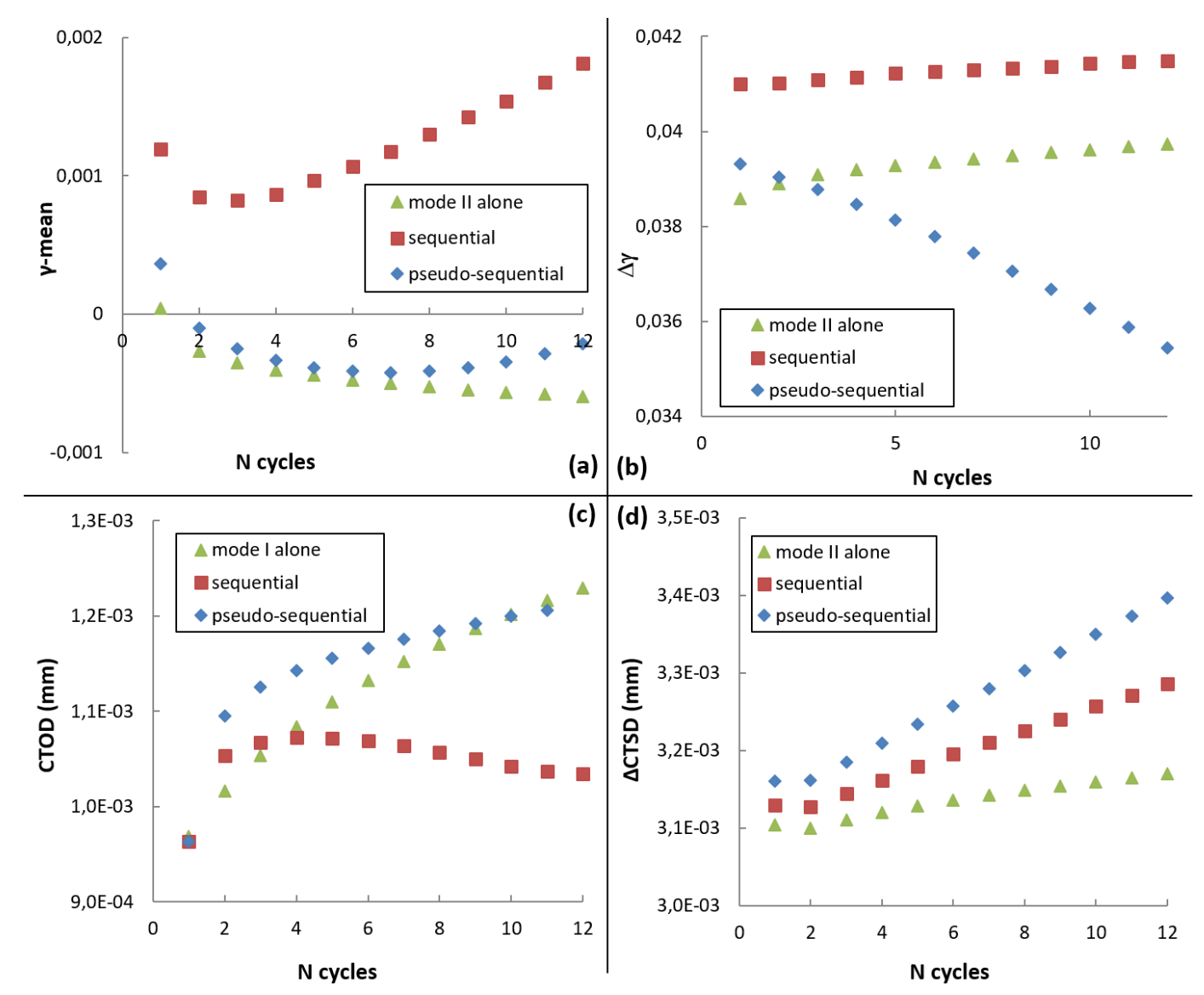

Figure 15: Plastic coupling between mode I and mode II for a crack submitted to sequential loading with $\Delta K_{I}=9 M P a \sqrt{m}$, and $\Delta K_{I I}=18 M P a \sqrt{m}$ a) in terms of mean shear strain $25 \mu \mathrm{m}$ ahead of the tip, b) in terms of shear strain range $25 \mu \mathrm{m}$ ahead of the tip, c) in terms of CTOD and d) in terms of CTSD.

erally considered as weakly dependent of the mean shear strain, so that the enhancement of shear strain ratchetting by sequential loading should not have a large impact on the crack growth rate.

The effect of mixed-mode loadings on the shear strain range ahead of the crack tip varies with the number of cycles. The shear strain range is initially increased compared to pure mode II, but this enhancement is only transient (during the first seven cycles for pseudo-sequential loading, but only during the first two cycles for sequential loading). Again, this can be qualitatively explained, considering the loading path on a small volume element ahead of the tip during the mode II cycle, and the moving yield locus (Fig 16b). A static compression while shearing (or, to a smaller extent, a residual compressive stress in sequential loading) reduces both the positive and negative shear stresses necessary to induce plastic flow, and thus increases the extent of plastic flow for a given shear stress range. Although this plastic flow has an axial component in contraction, its largest component is the shear strain (because the applied compression is only a small fraction of the yield stress), whose range is thus initially increased. However, due to kinematic hardening, 

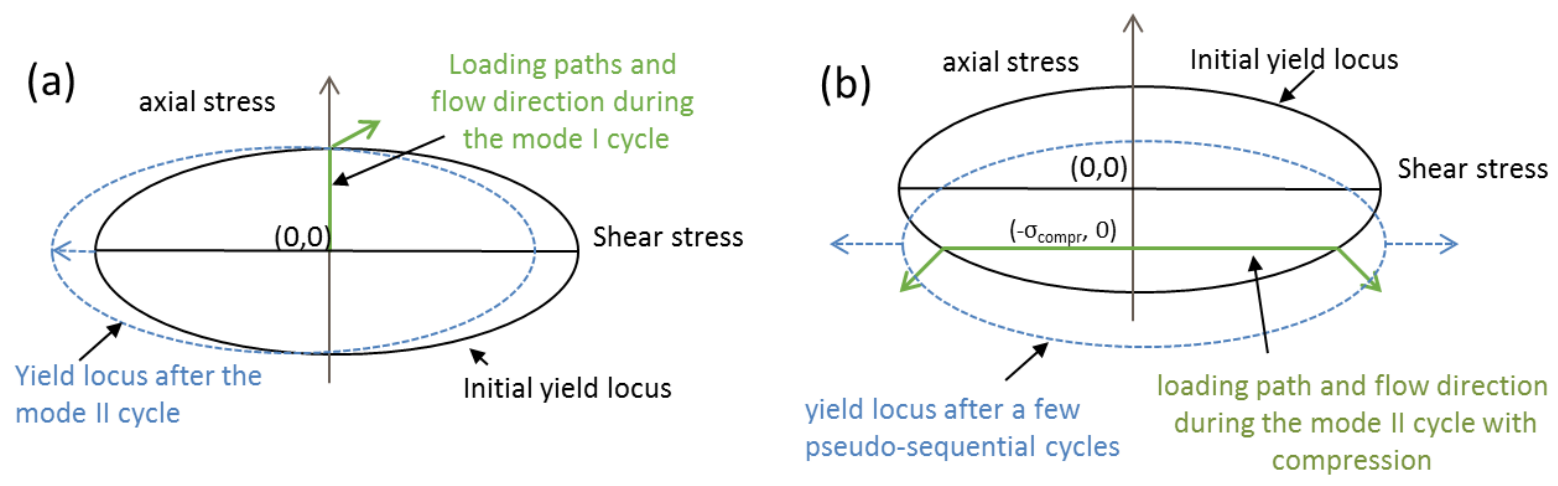

Figure 16: von Mises Yield locus in tension/ shear space, with superimposed loading paths on a volume element ahead of the crack tip, direction of plastic flow and associated shifting movements of the yield locus due to kinematic hardening, at min/max loads. a) shear strain ratchetting in sequential loading and b) transient enhancement of $\Delta \gamma$.

the yield domain progressively shifts downwards, until it is recentered around the applied compressive stress, so that the shear strain range is not increased anymore. Overall, the influence of mixed-mode loading on the shear strain range ahead of the tip is relatively weak.

Compared to pure mode I, for which some ratchetting of the $C T O D$ is predicted, both sequential and pseudo-sequential loadings initially enhance this phenomenon (as also reported in [11], where only 5 cycles were simulated), but again, this enhancement is only transient (until the $4^{t} \mathrm{~h}$ and $11^{t} h$ cycles, respectively in the present case) and then it turns into a reduction of the CTOD. By contrast, compared to pure mode II, both types of mixed-mode loadings clearly enhance the progressive increase of the $\triangle C T S D$, with a more pronounced effect of the pseudo-sequential loading.

Since these simulations are run on a stationary crack and thus do not capture the effect of a plastic wake, their interpretation in terms of crack growth rate has to remain careful. However, a comparison of the effects of pseudo-sequential loading on $\triangle \gamma, C T O D$ and $\triangle C T S D$ with those of sequential loading with similar effective SIFs suggests that the former might lead to a higher crack growth rate than the latter. Since in practice compression while shearing reduces $\Delta K_{I I}^{\text {effective }}$, the net effect in terms of crack growth rate should be the result of these two opposite intrinsic and extrinsic effects.

\section{Conclusions}

- Normal compression while shearing substantially extends coplanar growth under sequential mixed mode loading. Its complex effects (on crack face friction, oxidation, and wear, but also on crack tip plasticity and on the bifurcation angles) cannot be reduced to an enhancement of Coulomb's friction.

- Bifurcation occurs when $\Delta K_{I I}^{\text {effective }} / \Delta K_{I}^{\text {effective }}$, which progressively rises due to crack faces wear, reaches a material-dependent critical value around 2 . 
- Normal compression while shearing reduces the initial mode mixity ratio and slows down its rise during crack growth. This explains why it extends coplanar growth.

- The MTS criterion underestimates the extent of coplanar growth, while the MTSp criterion (which takes into account plasticity-induced stress redistribution at the crack tip) provides better predictions of the crack length at bifurcation, but does not predict truly coplanar growth before. The consideration of the contact and friction stresses present along the crack face improves the predictions.

- The coplanar crack growth rate under sequential or pseudo-sequential mode I + II loadings can be approximated by a sum of the growth rates during the mode I and mode II parts of the cycle, without any obvious synergistic effect, in spite of interactions between mode I and mode II in terms of crack tip plastic flow. It also correlates well with $\Delta K_{e q}^{\text {effective }}=\sqrt{\left(\Delta K_{I}^{\text {effective }}\right)^{2}+\left(\Delta K_{\text {shear }}^{\text {effective }}\right)^{2}}$.

- Since crack face friction and wear control the crack paths and growth kinetics, even in the absence of an applied normal compression, the challenge for structural applications is not just to choose the most appropriate bifurcation criterion and crack growth law, but also to take crack face roughness and wear into account in order to estimate the correct effective SIFS to use in these models.

\section{Acknowledgements}

The authors would like to acknowledge SNCF for its financial support and British Steel for providing the rail steel.

\section{Appendix A. Computation of nominal SIFs}

In order to choose the appropriate axial load and torque evolutions to drive the testing machine and follow the desired loading path in $\left(K_{I}, K_{I I}\right)$ space, an equation proposed in [20] for a crack in an infinitely long, thin tube relating the applied load/torque to the nominal SIFs and crack lengths was first used. This formula is valid for any crack length, if the stress field at the boundaries is uniform (no bending of the tube).

However, when the crack length becomes non negligible relative to the specimen diameter, the sample will tend to bend due to the asymmetry induced by the crack (see figure A.17.a). Depending on the bending stiffness of the clamping device, a high or weak bending moment will resist this effect. The stress field at the boundaries may not be uniform, and the aforementioned equations may not be valid anymore.

Indeed, as shown on figure A.17.b \& c, two FEM computations performed with the same model and applied force, but with a uniform stress (no setup bending stiffness) or a uniform axial displacement (no rotation allowed, infinite bending stiffness) yield very different SIFs: $K_{I}=81.6 \mathrm{MPa} \sqrt{m} \& K_{I}=20.3$ $M P a \sqrt{m}$ respectively. The real behavior lies somewhere between those two extreme cases (negligible \& 


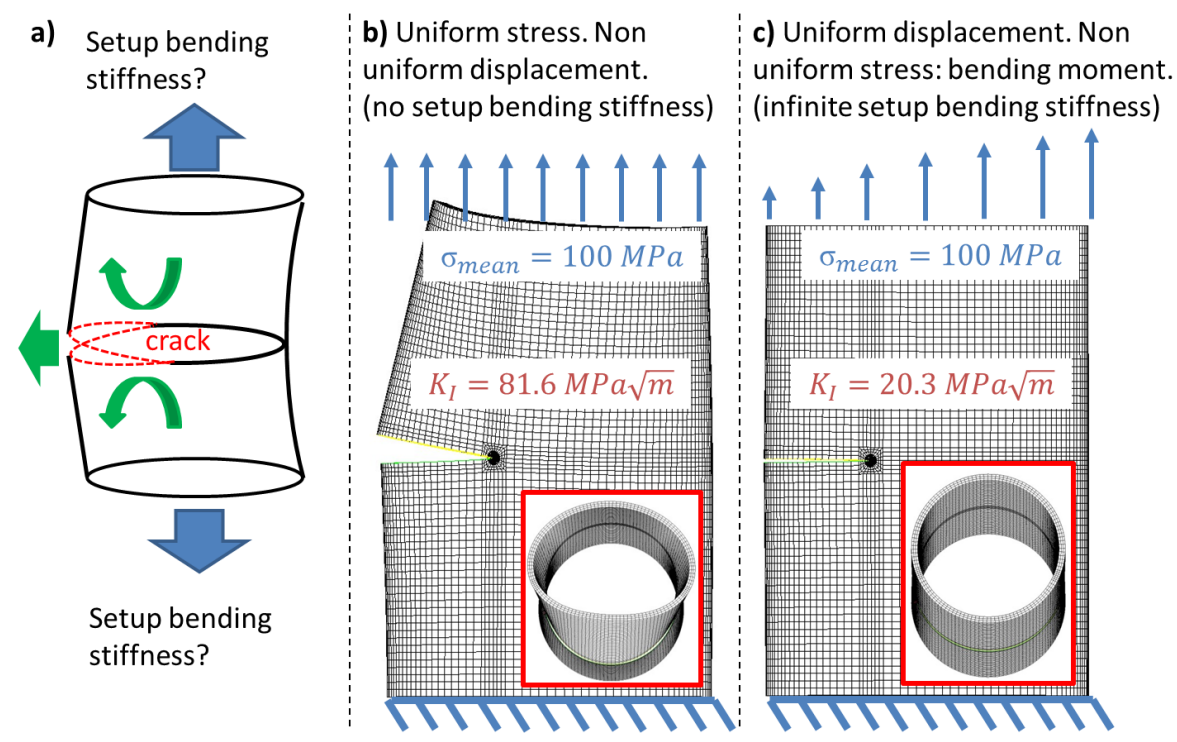

Figure A.17: Influence of the setup bending stiffness (a). FEM computation (side view, and top view in red square) with identical tensile force, but with a uniform tensile stress (b), and with a uniform vertical displacement (c). Crack length $a=15$ $\mathrm{mm}$, specimen length $36 \mathrm{~mm}$, displacements amplified by a factor 10

infinite stiffness).

The nominal SIFs used in this work were obtained using 3D FEM computations with a uniform axial imposed displacement, and an "effective tube length" adjusted so that the FEM computations gave similar SIFs to those obtained from DIC fields (see Appendix B) for which nonlinearities were very limited (very little plasticity, no contact between the crack faces). The evolution of $K_{I} \& K_{I I}$ obtained from the analytical expressions proposed in [20], DIC fields, and FEM computations are plotted on figure A.18. As expected, the longer the crack, the larger the error made using the analytical expressions obtained for an infinite tube.
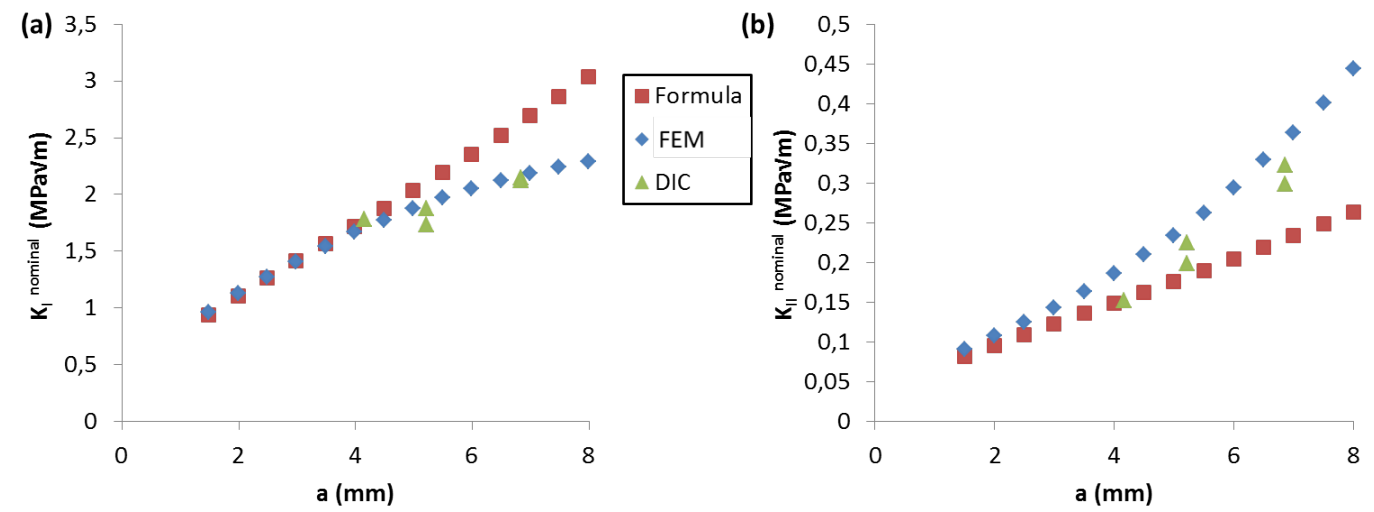

Figure A.18: Evolution of (a) $K_{I}(a)$ for a $1 \mathrm{kN}$ axial load and (b) $K_{I I}(a)$ for a $1 \mathrm{Nm}$ torque, obtained using the formulae in [20], XFEM computations and DIC. 


\section{Appendix B. Crack length monitoring using DIC}

The algorithm used to determine the crack tip position (and thus derive the crack growth rate) by correlation of two stereo images is described in figure B.19.a. These images are captured at peak tensile load and after a small elastic unloading, for which case the assumptions made by Williams to obtain a series expansion of the near-tip displacement field (that is: stress-free crack faces and linear elastic behavior) are valid. At each possible crack tip location, only a part of the DIC field is used, as shown on figure B.19.b. $R_{\text {int }}$ is chosen sufficiently large to avoid the subsets which overlap the crack, and for which the correlation is wrong.
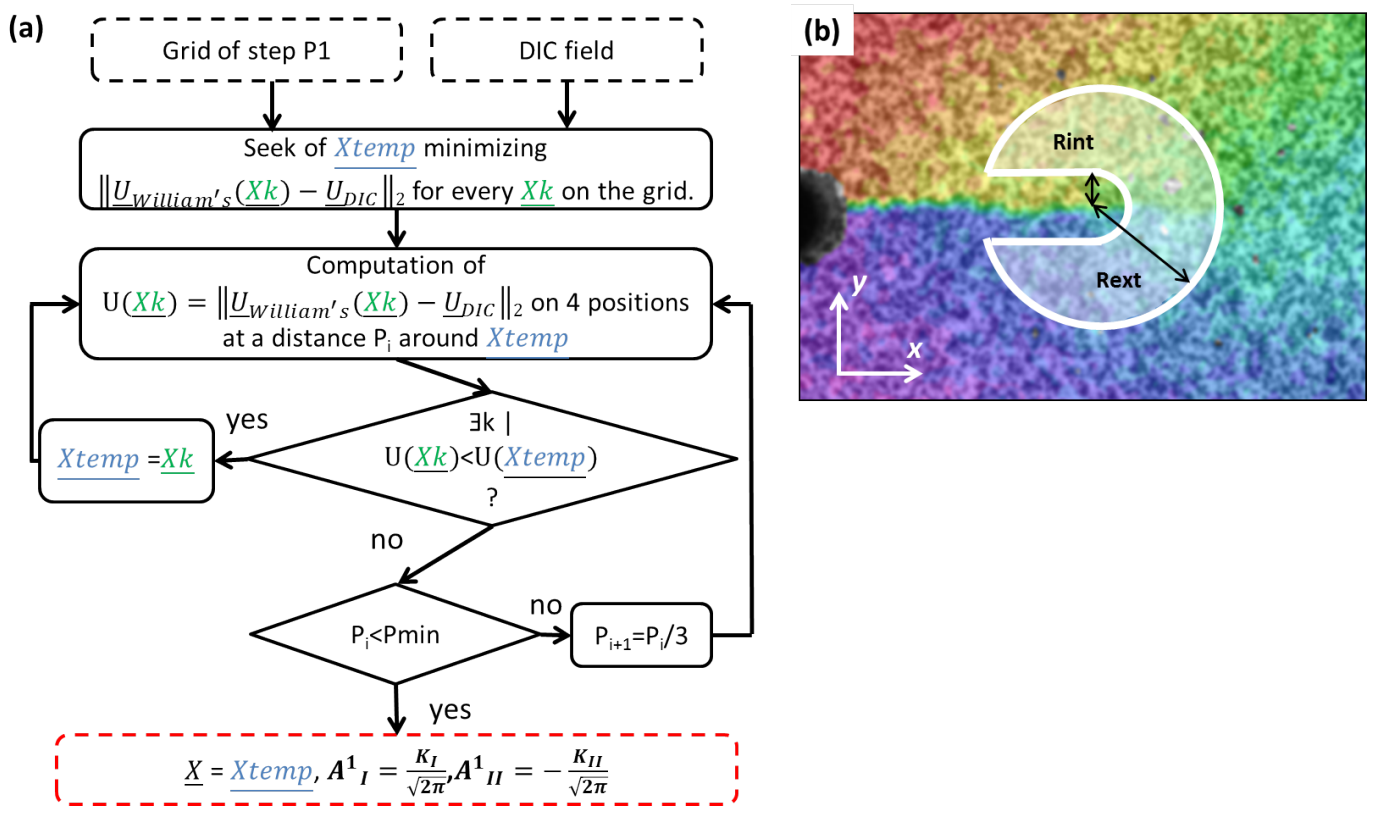

Figure B.19: (a) Pattern Search (PS) algorithm with William's series expansion of the near tip displacement field. Xtemp represents the current supposed crack tip and $\underline{X k}$ the tested crack tip positions. (b) DIC field (horizontal displacement), with the shape of the zone used in the PS algorithm. Rext $=1.2 \mathrm{~mm}$ and Rint $=0.2 \mathrm{~mm}$.

Noting the horizontal and vertical displacements $u_{x}$ and $u_{y}$ respectively, with $G$ the shear modulus and $k=(3-\nu) /(1+\nu)$ (plane stress hypothesis), William's expansion series writes:

$$
\begin{aligned}
& u_{x}=\sum_{n=0}^{N} \frac{A_{I}^{n}}{2 G} r^{\frac{n}{2}}\left(\left(\kappa+\frac{n}{2}+(-1)^{n}\right) \cos \left(\frac{n}{2} \theta\right)-\frac{n}{2} \cos \left(\left(\frac{n}{2}-2\right) \theta\right)\right) \\
& +\sum_{n=0}^{N} \frac{A_{I}^{n}}{2 G} r^{\frac{n}{2}}\left(\left(-\kappa-\frac{n}{2}+(-1)^{n}\right) \sin \left(\frac{n}{2} \theta\right)+\frac{n}{2} \sin \left(\left(\frac{n}{2}-2\right) \theta\right)\right)
\end{aligned}
$$




$$
\begin{aligned}
u_{y} & =\sum_{n=0}^{N} \frac{A_{I}^{n}}{2 G} r^{\frac{n}{2}}\left(\left(\kappa-\frac{n}{2}-(-1)^{n}\right) \sin \left(\frac{n}{2} \theta\right)+\frac{n}{2} \sin \left(\left(\frac{n}{2}-2\right) \theta\right)\right) \\
& +\sum_{n=0}^{N} \frac{A_{I I}^{n}}{2 G} r^{\frac{n}{2}}\left(\left(\kappa-\frac{n}{2}+(-1)^{n}\right) \cos \left(\frac{n}{2} \theta\right)+\frac{n}{2} \cos \left(\left(\frac{n}{2}-2\right) \theta\right)\right)
\end{aligned}
$$

The rigid body translations $t_{x}$ and $t_{y}$ are contained in the order 0 terms:

$$
\begin{gathered}
t_{x}=\frac{A_{I}^{0}}{2 G}(\kappa+1)=\frac{4 A_{I}^{0}}{E} \\
t_{y}=\frac{A_{I I}^{0}}{2 G}(\kappa+1)=\frac{4 A_{I I}^{0}}{E}
\end{gathered}
$$

The stress intensity factors are contained in the order 1 terms:

$$
\begin{gathered}
K_{I}=\sqrt{2 \pi} A_{I}^{1} \\
K_{I I}=-\sqrt{2 \pi} A_{I I}^{1}
\end{gathered}
$$

The rigiby body rotation $\Omega$ and the T-stress $T$ are contained in the order 2 terms:

$$
\begin{gathered}
\Omega=\frac{A_{I I}^{2}}{2 G}(\kappa+1)=\frac{4 A_{I I}^{2}}{E} \\
T=\frac{A_{I}^{2}}{2 G}(\kappa+1) E=4 A_{I}^{2}
\end{gathered}
$$

The parameters used in this study are: $R_{\text {int }}=0.2 \mathrm{~mm}, R_{\text {ext }}=1.2 \mathrm{~mm}$, grid step $P_{1}=0.1 \mathrm{~mm}$, PS algorithm steps from $P=0.033 \mathrm{~mm}$ to $P=0.0037$, order of the William's expansion terms: from 0 to 7 . 


\section{References}

[1] B. Dylewski, M. Risbet, S. Bouvier, The tridimensional gradient of microstructure in worn rails - Experimental characterization of plastic deformation accumulated by RCF, WEAR 392-393 (2017) 50-59.

[2] S. L. Wong, P. E. Bold, M. W. Brown, R. J. Allen, A branch criterion for shallow angled rolling contact fatigue cracks in rails, Wear 191 (1996) 45-53.

[3] S. Bogdanski, M. Olzak, J. Stupnicki, Numerical modelling of a 3d rail rcf 'squat'-type crack under operating load, Fat. Fract. Eng. Mater. Struct. 21 (1998) 923-935.

[4] S. H. Mai, A. Gravouil, M. L. Nguyen-Tajan, B. Trolle, Numerical simulation of rolling contact fatigue crack growth in rails with the rail bending and the frictional contact, Eng Fract Mech 174 (2017) 196-206.

[5] T. Bonniot, Fatigue crack growth under non proportional mixed-mode loading in rail steel. From experiment to simulation., Ph.D. thesis, Ecole Polytechnique (18 November 2019).

URL https://tel.archives-ouvertes.fr/tel-02443488

[6] T. Bonniot, V. Doquet, S. H. Mai, Mixed mode II and III fatigue crack growth in a rail steel., Int J Fatigue 115 (October 2018) (2018) 42-52.

[7] P. Bold, Multiaxial fatigue crack growth in rails., Ph.D. thesis, University of Sheffield (1990).

[8] S. L. Wong, P. E. Bold, M. W. Brown, R. J. Allen, Fatigue crack growth rates under sequential mixed-mode I and II loading cycles, Fat. Fract. Eng. Mater. Struct. 23 (2000) 667-674.

[9] S. L. Wong, P. E. Bold, M. W. Brown, R. J. Allen, Two measurement techniques for determining effective stress intensity factors, Fat. Fract. Eng. Mater. Struct. 23 (2000) 659-666.

[10] M. Akama, Fatigue crack growth under mixed loading of tensile and in-plane shear modes, QR of RTRI 44 (2003) 65-71.

[11] V. Doquet, S. Pommier, Fatigue crack growth under non-proportional mixed-mode loading in ferritic-pearlitic steel, Fat. Fract. Eng. Mater. Struct. 27 (2004) 1051-1060.

[12] M. Akama, A. Kiuchi, Long co-planar mode III fatigue crack growth under non-proportional mixed mode loading in rail steel, J rail and rapid transit 226 (2012) 489-500.

[13] M. Akama, Fatigue Crack Growth under Non-Proportional Mixed Mode Loading in Rail and Wheel Steel Part 1: Sequential Mode I and Mode II Loading, Appl. Sci. 9 (2019).

[14] V. Doquet, G. Bertolino, Local approach to fatigue cracks bifurcation, Int J Fatigue 30 (2008) 942-950.

[15] S. Beretta, S. Folett, K. Valiullin, Fatigue crack propagation and threshold for shallow micro-cracks under out-of-phase multiaxial loading in a gear steel, Eng Fract Mech 77 (2010) 1835-1848.

[16] G. Tarantino, Shear-mode propagation of short cracks under rolling contact fatigue., Ph.D. thesis, Politecnico Di Milano (2011).

[17] M. G. Tarantino, S. Beretta, S. Foletti, J. Lai, A comparison of Mode III threshold under simple shear and RCF conditions, Eng Fract Mech 78 (8) (2011) 1742-1755.

[18] M. G. Tarantino, S. Beretta, S. Foletti, I. Papadopoulos, Experiments under pure shear and rolling contact fatigue conditions: Competition between tensile and shear mode crack growth, Int J Fatigue 46 (2013) 67-80.

[19] F. Erdogan, M. Ratwani, A circumferential crack in a cylindrical shell under torsion, International Journal of Fracture Mechanics 8 (1972) 87-95.

[20] H. Tada, P. Paris, G. Irwin, The stress analysis of cracks handbook, Del. Research Corporation, Hellertown, Pennsylvania, 1973.

[21] T. Bonniot, V. Doquet, S. H. Mai, Determination of effective Stress Intensity Factors under mixed-mode from DIC fields in presence of contact stresses and plasticity., To appear in Strain (2019). doi:10.1111/str.12332.

[22] V. Doquet, M. Abbadi, Q. H. Bui, A. Pons, Influence of the loading path on fatigue crack growth under mixed-mode loading, Int J Fracture 159 (2009) 219-232. 
[23] M. C. Smith, R. A. Smith, Toward an understanding of mode II fatigue crack growth, Basic Questions in Fatigue 1 (1988) $260-280$.

[24] J. F. Archard, Contact and Rubbing of Flat Surface, Journal of Applied Physics 24 (1953) 981-988.

[25] P. Arnaud, S. Fouvry, A. Mignot, P. Neubauer, Contact size, frequency and cyclic normal force effects on Ti-6Al-4V fretting wear processes: An approach combining friction power and contact oxygenation, Tribology International 113 (2017) 460-473.

[26] P. Arnaud, Etude expérimentale et numérique de l'usure et de son influence sur les mécanismes de fissuration en fretting et fretting fatigue, Ph.D. thesis, Ecole centrale de Lyon (2018).

[27] P. Arnaud, S. Fouvry, S. Garcin, A numerical simulation of fretting wear profile taking account of the evolution of third body layer, WEAR 376-377 (2017) 1475-1488.

[28] P. Arnaud, S. Fouvry, A dynamical FEA fretting wear modeling taking into account the evolution of debris layer, WEAR 412 (2018) 92-108

[29] J. Ding, I. R. McColl, S. B. Leen, P. H. Shipway, A finite element based approach to simulating the effects of debris on fretting wear, WEAR 263 (2007) 481-491.

[30] B. D. Leonard, A. Ghosh, F. Sadeghi, S. Shinde, M. Mittelbach, Third body modeling in fretting using the combined finite-discrete element method, Int J Solids Struct. 51 (2014) 1375-1389.

[31] H. Haddad, M. Guessasma, J. Fortin, A DEM-FEM coupling based approach simulating thermomechanical behaviour of frictional bodies with interface layer, Int J Solids Struct. 81 (2016) 203-218.

[32] A. Ghosh, W. Wang, F. Sadeghi, An elastic-plastic investigation of third body effects on fretting contact in partial slip, Int J Solids Struct. 81 (2016) 95-109.

[33] T. Yue, M. Abdel Wahab, A Numerical Study on the Effect of Debris Layer on Fretting Wear, Materials 9 (2016).

[34] V. Done, D. Kesavan, R. Murali Krishna, T. Chaise, D. Nelias, Semi analytical fretting wear simulation including wear debris, Tribology International 2019 (2017) 1-9.

[35] P. Dahlin, M. Olsson, The effect of plasticity on incipient mixed-mode fatigue crack growth, Fat. Fract. Eng. Mater. Struct. 26 (2003) 577-588

[36] V. Doquet, A. Pineau, Extra hardening due to cyclic nonproportional loading of an austenitic stainless steel, Scripta Metallurgica et Materialia 24 (1990) 433-438.

[37] J. Leblond, J. Frelat, Crack kinking from an initially closed crack, IJSS 37 (2000) 1595-1614. 